Review

\title{
Theoretical and Computational Studies of Peptides and Receptors of the Insulin Family
}

\author{
Harish Vashisth \\ Department of Chemical Engineering, University of New Hampshire, 33 Academic Way, \\ Durham, NH 03824, USA; E-Mail:Harish.Vashisth@unh.edu; Tel.: +1-603-862-2483; \\ Fax: +1-603-862-3747
}

Academic Editor: Christian Brix Folsted Andersen

Received: 26 August 2014 / Accepted: 28 January 2015 / Published: 11 February 2015

\begin{abstract}
Synergistic interactions among peptides and receptors of the insulin family are required for glucose homeostasis, normal cellular growth and development, proliferation, differentiation and other metabolic processes. The peptides of the insulin family are disulfide-linked single or dual-chain proteins, while receptors are ligand-activated transmembrane glycoproteins of the receptor tyrosine kinase (RTK) superfamily. Binding of ligands to the extracellular domains of receptors is known to initiate signaling via activation of intracellular kinase domains. While the structure of insulin has been known since 1969, recent decades have seen remarkable progress on the structural biology of apo and liganded receptor fragments. Here, we review how this useful structural information (on ligands and receptors) has enabled large-scale atomically-resolved simulations to elucidate the conformational dynamics of these biomolecules. Particularly, applications of molecular dynamics (MD) and Monte Carlo (MC) simulation methods are discussed in various contexts, including studies of isolated ligands, apo-receptors, ligand/receptor complexes and intracellular kinase domains. The review concludes with a brief overview and future outlook for modeling and computational studies in this family of proteins.
\end{abstract}

Keywords: insulin; insulin-like growth factors; receptor tyrosine kinases; computer simulations; docking; enhanced sampling; signal transduction 


\section{Introduction}

\subsection{Brief Historical Account}

Insulin, a peptide hormone described as an "enduring medical miracle" [1] and the "protein of the 20th century" [2], was discovered in 1922 by the team of Frederick Banting, Charles Best, James Collip and John Macleod [3-6]. Insulin is secreted by pancreatic $\beta$ cells [7] and is primarily responsible for glucose homeostasis in higher organisms. Early successes of insulin administration in dogs and then in humans [8,9] led to the large-scale production of insulin [10] and discoveries of its prolonged action [11,12]. Later, the biosynthetic pathway of insulin was discovered [13], radioimmunoassays for measuring minute circulating amounts of insulin were developed [14,15], the concept of insulin analogues was introduced [16-18], the physicochemical basis for rapid time-action of some insulin analogues was elucidated [19,20] and other methods of insulin delivery were explored [21-25].

\subsection{Structural Biology of the Insulin Family}

On the structural biology front, insulin is also considered a model protein, as it was the first protein to have its primary structure sequenced [26], followed by the determination of its three-dimensional structure [27], a discovery that has inspired extensive work on the structural studies of various insulin forms and related ligands [28-42]. Soon came evidence for a cell surface receptor for insulin, the insulin receptor (IR) [43], followed by its classification as a receptor tyrosine kinase (RTK) [44,45] and the determination of its primary sequence, as well as of a related homologue, type-1 insulin-like growth factor receptor (IGF1R) [46-48]. These findings collectively suggested that insulin shares its signaling pathways with other ligands, such as growth factors, mainly type-1 and type-2 insulin-like growth factors (IGF1 and IGF2), which exert their physiological effects via IGF1R, but can also cross-react with IR [49,50]. In fact, the mammalian insulin peptide family consists of insulin, IGF1, IGF2, seven relaxin peptides, six soluble IGF binding proteins (IGFBPs), IR, IGF1R and insulin receptor-related receptor (IRR) [51,52]. The IGFs/IGF1R system has been implicated in tumorigenesis, cancer development and progression [53-61], while IRR has been suggested to function as an alkali sensor [62]; we will focus here only on interactions among insulin, IGF1, IGF2, IR and IGF1R.

Although intact structures of full-length receptors remain elusive and have been listed among highly desired structures [63], the structural biology community has made consistent and steady progress in solving the structures of various parts of receptors in different forms:

(1) Intracellular kinase domains: The first crystal structures of the human IR kinase domain (IRKD) in inactive and active forms were determined in 1994 [64] and 1997 [65], respectively. Similar inactive and active structures of the IGF1R kinase domain (IGF1RKD) were later determined in 2001 [66] and 2002 [67], respectively.

(2) Apo-ectodomains: In 1998 came the first breakthrough when Colin Ward and colleagues reported the atomic crystal structure of the first three domains of IGF1R [68]. The next year, they further reported the first electron microscopy (EM) images of the human insulin receptor ectodomain and its complexes with antibody fragments [69]. After a gap of seven years, the same group reported ground-breaking 
discoveries on the crystal structures of the first three domains of IR [70], as well as of the IR ectodomain (IR $\Delta \beta$ ) [71]. The original IR ectodomain structure (PDB Code 2DTG) was later improved (PDB Code $3 \mathrm{LOH}$ ) to include the previously unresolved C-terminal region of the IR $\alpha$-chain (also known as the $\alpha \mathrm{CT}$ peptide) [72]. Consistent with small-angle X-ray scattering (SAXS) data, a homology model of the IGF1R ectodomain (IGF1R $\Delta \beta$ ) based on IR crystal structures was constructed in 2009 by Whitten et al. [73]. During the aforementioned seven-year gap, Luo et al. [74] reported the quaternary structure of the insulin-IR complex based on EM images. We note that this quaternary structure has been under debate due to inconsistency with the crystal structure of the IR ectodomain $[2,49,71,75]$.

(3) Ligand-bound ectodomains: In other major breakthroughs, an international team, comprised of Colin Ward, Michael Lawrence, Michael Weiss and colleagues, reported a series of structures of insulin bound to various constructs of the IR ectodomain in 2013 [76] and 2014 [77].

(4) Transmembrane domain: $\mathrm{Li}$ et al. [78] have recently reported a solution structure of the transmembrane domain of human IR using NMR spectroscopy.

No other experimental structures of IR or IGF1R have been reported to date (to the best of our knowledge). To gain a better understanding of the significance of these structures and structure-function relationships in the IR family, we refer interested readers to a series of earlier comprehensive reviews [2,5,49,50,52,75,79-91]. Additionally, the following reviews, commentary and perspective articles on the insulin family are recommended [51,92-101]. In this short review, we instead will focus on new questions raised by the outlined structures concerning the conformational dynamics of these ligands and/or receptors that have been answered using detailed theory, modeling and simulation approaches. In the following, we first briefly review key structural details and the domain nomenclature of ligands and receptors; then, we describe the modeling and simulation approaches that have been applied and, finally, summarize the applications of these methods to individual ligand/receptor systems. We conclude the review with a brief section on future outlooks and unanswered questions that can be potentially addressed using biophysical simulations.

\section{Structural Details: Architecture and Nomenclature}

\subsection{Ligands}

Insulin is synthesized as a single-chain molecule of $\sim 110$ residues, also known as preproinsulin, which becomes proinsulin on immediate removal of the signal sequence and then mature insulin on cleavage of the connecting peptide by enzymes. Therefore, the final insulin monomer is composed of two chains, an A chain with 21 residues and a B chain with 30 residues. However, homologous growth factors IGF1 (70 residues) and IGF2 (67 residues) are single-chain polypeptides, each with four domains designated conventionally as $\mathrm{B}, \mathrm{C}, \mathrm{A}$ and $\mathrm{D}$ (from the $\mathrm{N}$-terminus to the $\mathrm{C}$-terminus), respectively. The $\mathrm{A}$ and $\mathrm{B}$ domains of IGFs are similar to the A and B chains of insulin, while insulin lacks the C and D domains, unlike IGFs. However, each ligand has three disulfide bonds, and IGFs are also slightly larger in size than insulin due to additional domains. The three-dimensional folds of all ligands are shown in Figure 1. Similar structural elements among ligands include two $\alpha$-helices (yellow) in A chains/domains and a central $\alpha$-helix (black) in the B chains/domains. Key differences are in the $\mathrm{N}$ - and C-termini 
of B chains/domains: the N-terminus of insulin B-chain can be either extended (T-state like IGFs) or helical (R-state), while the $\mathrm{C}$-terminus of insulin B-chain can form a $\beta$-sheet, unlike the unstructured conformation seen for IGFs. The C and D domains of IGFs, absent in mature insulin, are devoid of well-defined secondary structure elements.
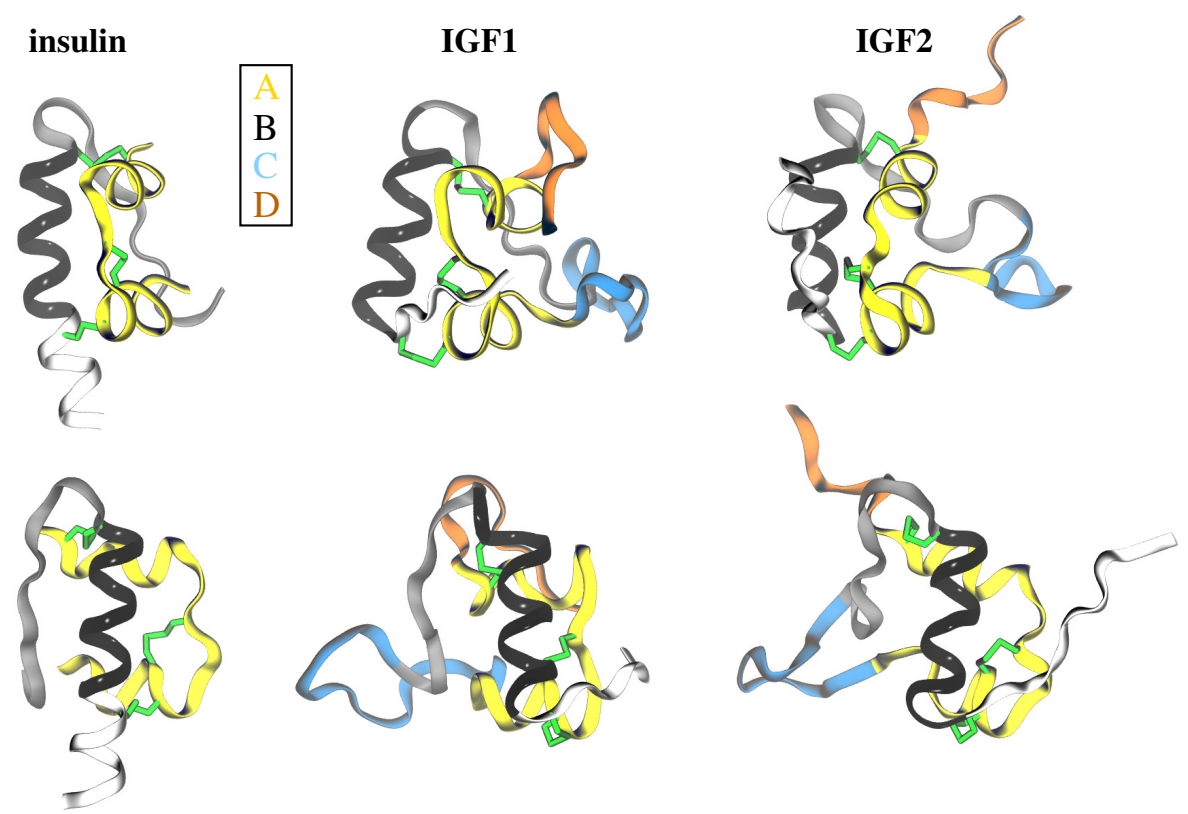

Figure 1. Cartoon representations of the three-dimensional folds of insulin, IGF1 and IGF2: A chains/domains are yellow; $\mathrm{C}$ and $\mathrm{D}$ domains are blue and orange; while parts of $\mathrm{B}$ chains/domains are shown in white (N-terminus), black (middle helix) and gray (C-terminus). Disulfide bonds are represented by greens sticks. (top) Side views focusing simultaneously on A and B chains/domains; (bottom) views focusing on the B chains/domains with other parts of ligands hidden behind.

The unique features present in the $\mathrm{N}$ - and $\mathrm{C}$-termini of the insulin B-chain allow the hormone to dimerize or hexamerize (in the presence of zinc or phenol) via self-assembly. Such insulin hexamers can exist in a dynamic equilibrium between three allosteric states, known as $\mathbf{T}_{6}, \mathbf{T}_{3} \mathbf{R}_{3}$ and $\mathbf{R}_{6}$ [28-37], that can be shifted to $\mathbf{R}_{6}$ only by phenolic species [102-104]. However, one can achieve the $\mathbf{T}_{3} \mathbf{R}_{3}$ state by phenolic species or concentrated anionic medium or both. Six hydrophobic pockets exist for phenolic ligands in $\mathbf{R}_{6}$ hexamers, but not in $\mathbf{T}_{6}$ hexamers. The overall arrangement of insulin monomers in three hexameric allosteric states is shown in Figure 2. No structural evidence exists for the oligomerization or conformational change in IGFs, but it has been suggested that the N-terminus of IGF1 may undergo a conformational change that affects its receptor binding affinity [105]. 

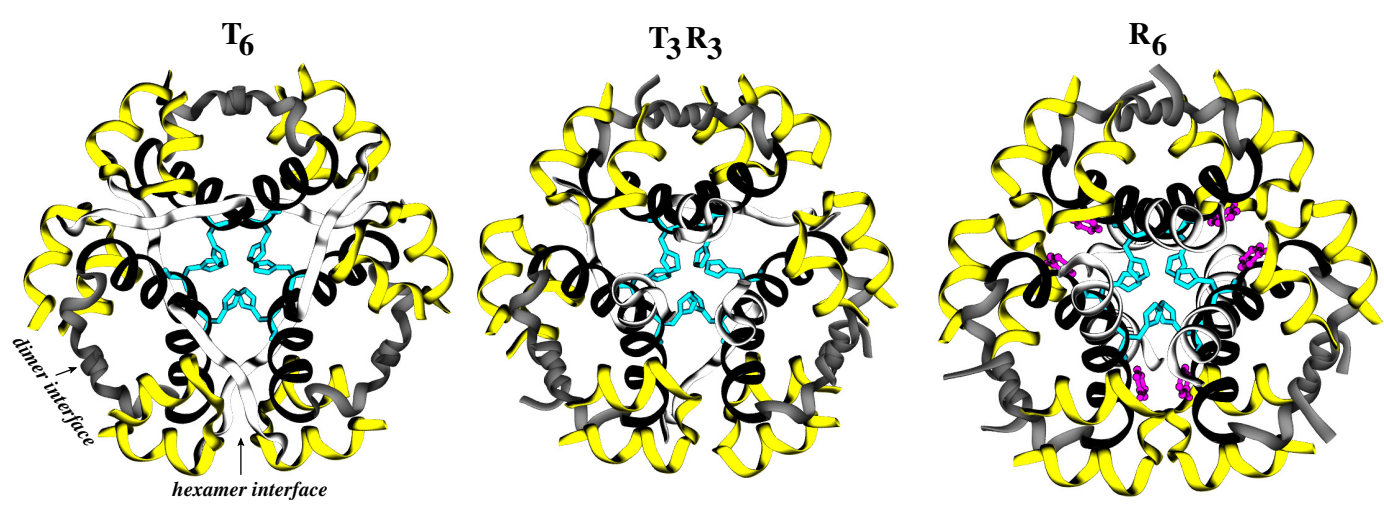

Figure 2. Three allosteric forms of insulin hexamers. $\mathbf{T}_{6}, \mathbf{T}_{3} \mathbf{R}_{3}$ and $\mathbf{R}_{6}$ insulin hexamers are shown in cartoon representations. The color scheme for the insulin monomers is the same as in Figure 1. Additionally, six zinc-coordinating histidine residues from six B chains (cyan) and six phenols (magenta; $\mathbf{R}_{6}$ only) are shown in stick representations. Disulfide bonds are omitted for clarity. Approximate locations of two key interfaces (dimer and hexamer-forming) are also marked (left).

\subsection{Receptors}

Insulin and insulin-like growth factors initiate signaling by binding to their cognate cell-surface receptors, namely IR and IGF1R; although both receptors can bind insulin, IGF1 and IGF2 with differing affinities. The sequences of receptor precursors contain $\sim 1370$ (IR) and $\sim 1367$ (IGF1R) residues, respectively [46-48]. Each receptor is a $\sim 300-350-\mathrm{kDa}$ protein having two subunits, each with two chains ( $\alpha$ and $\beta$ ). The $\alpha$-chains are entirely extracellular, and the $\beta$-chains have parts on the extracellular side, in the membrane and on the intracellular side. The formation of $\alpha_{2}-\beta_{2}$ mature receptors requires dimerization, glycosylation [106-108] and proteolytic processing of precursors. Among RTKs, the covalently-linked $[109,110]$ homodimeric architecture of highly homologous IR and IGF1R is unique in that these receptors require domain rearrangements rather than receptor dimerization for activation [50].

Each subunit in receptor homodimers starts with two leucine-rich domains (L1 and L2) separated by a cysteine-rich (CR) domain and followed by three type III fibronectin repeats (F1, F2 and F3) on the extracellular side. The C-terminus of F3 is connected to the cytoplasmic kinase modules via single-pass transmembrane domains. The structural evidence of domain organization in IR and IGF1R came from various crystal structures: the L1-CR-L2 motifs from IGF1R (PDB Code 1IGR) [68] and IR (PDB Code 2HR7) [70], and IR $\Delta \beta$ (PDB Codes 2DTG and 3LOH) [71,72]. A homology model of IGF1R $\Delta \beta$ validated using small-angle X-ray scattering (SAXS) data further confirmed the similarity in the overall topology of IR and IGF1R [73]. As depicted in Figure 3, the ectodomains of both receptors have a symmetric folded-over $(\wedge$-shaped) architecture with the following key features: (1) the L1-CR-L2 domains of one subunit and the F1-F2-F3 domains of the other subunit form one binding pocket on each side of the receptor; (2) the major contact surfaces between two subunits are at the L1-F2 interfaces near each binding pocket and at the L2-F1 interfaces near the apex of each ectodomain; (3) the $\alpha$ CT helical peptide located on the L1 surface is also part of each ligand binding pocket; and (4) the F3 domains ("legs" of receptors) are proximal to the membrane. 

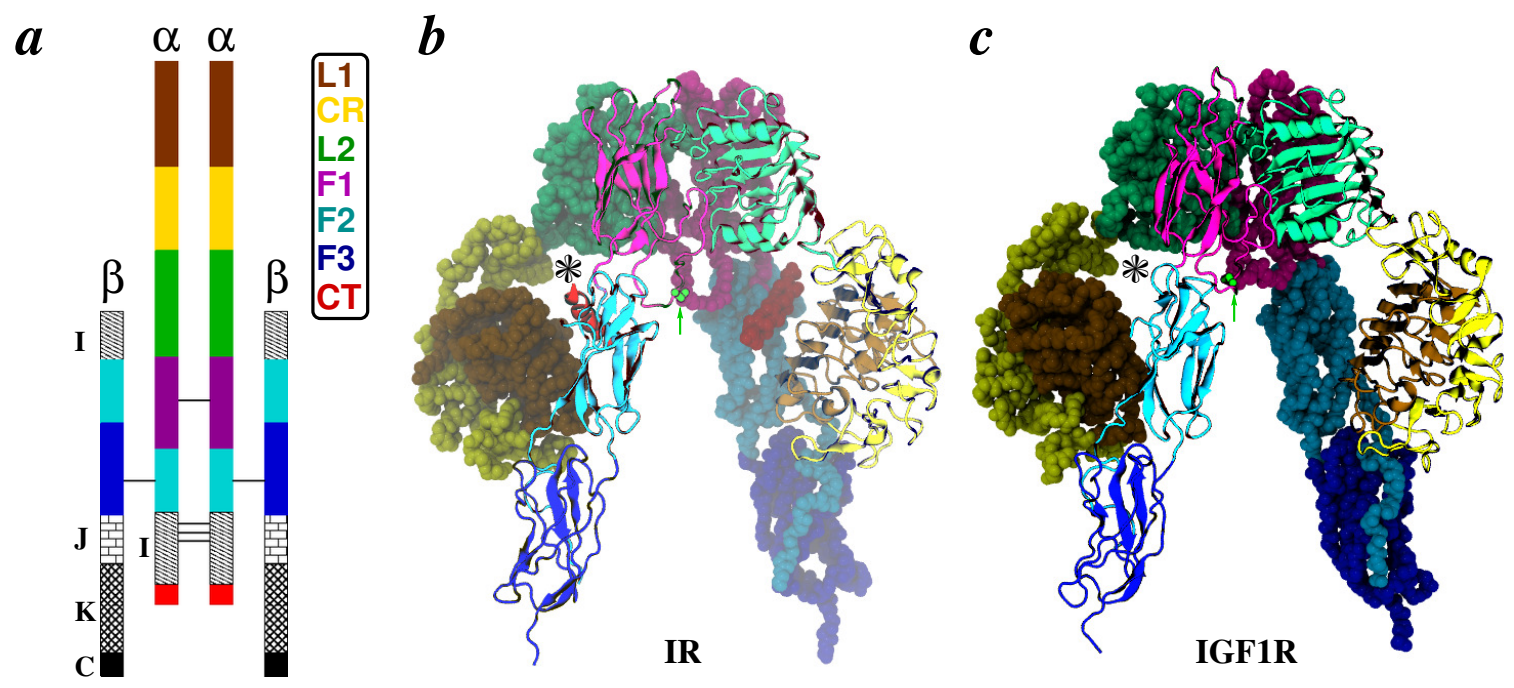

Figure 3. The domain organization and structures of receptor ectodomains. (a) A schematic of the domain organization in full-length receptors is shown. The $\alpha$ - and $\beta$-chains, as well as receptor domains are labeled. Labels are in the same color as the domains, except insert domains (I), juxtamembrane regions $(\mathbf{J})$, kinase modules $(\mathbf{K})$ and C-terminal tails (C), all of which are depicted by filled patterns; (b,c) Three-dimensional folds of IR $\Delta \beta$ (PDB Code 3LOH) and IGF1R $\Delta \beta$ (homology model of Whitten et al. [73]) are shown with domains of one subunit as space-filling, while identical domains of the other subunit are shown as cartoons. All domains are uniquely colored as in (a). One intersubunit disulfide-bond resolved at $\mathrm{Cys}^{524}$ in IR $\Delta \beta$ and modeled at $\mathrm{Cys}^{514}$ for IGF1R $\Delta \beta$ is shown in green sticks (indicated by green arrows). The $\alpha \mathrm{CT}$ peptide is shown only for IR $\Delta \beta$, as it was resolved [72] after publication of the homology model of IGF1R $\Delta \beta$ [73]. The location of one out of two binding pockets in each receptor ectodomain is marked by an asterisk; see Figure $4 \mathrm{a}$ for a side view of this binding pocket.

\subsubsection{Conformational Metrics of Receptors}

We have previously defined some quantitative geometric measures for receptor ectodomains [111,112], such as the radius of gyration $\left(\mathrm{R}_{\mathrm{g}}\right)$ of each binding pocket, the buried surface areas between the L1/F2 and L2/F1 domains and the interdomain hinge angles, as well as the interhinge distances based on the centers of mass (COM) of each domain. These geometric measures of ectodomains are shown in Figure 4 and suggest that: (1) the L1-L2 hinges are at $\sim 90^{\circ}$ in each receptor; (2) the F1-F2 hinges are at $\sim 161^{\circ}$ (IR) and $\sim 166^{\circ}$ (IGF1R); (3) the apical L2-F1 hinges are at $\sim 82^{\circ}$ in each receptor; (4) interhinge distances between the L1-L2 and F1-F2 hinge points are at $51 \AA$ (IR) and $50 \AA$ (IGF1R); (5) the $\mathrm{R}_{\mathrm{g}}$ values are $20 \AA$ (IR) and $22.5 \AA$ (IGF1R); (6) the buried surface areas at the L1/F2 interfaces are $\sim 900 \AA^{2}$ (IR) and $\sim 1300 \AA^{2}$ (IGF1R); and (7) the buried surface areas at the L2/F1 interfaces are $\sim 1100 \AA^{2}$ (IR) and $\sim 1,600 \AA^{2}$ (IGF1R). 

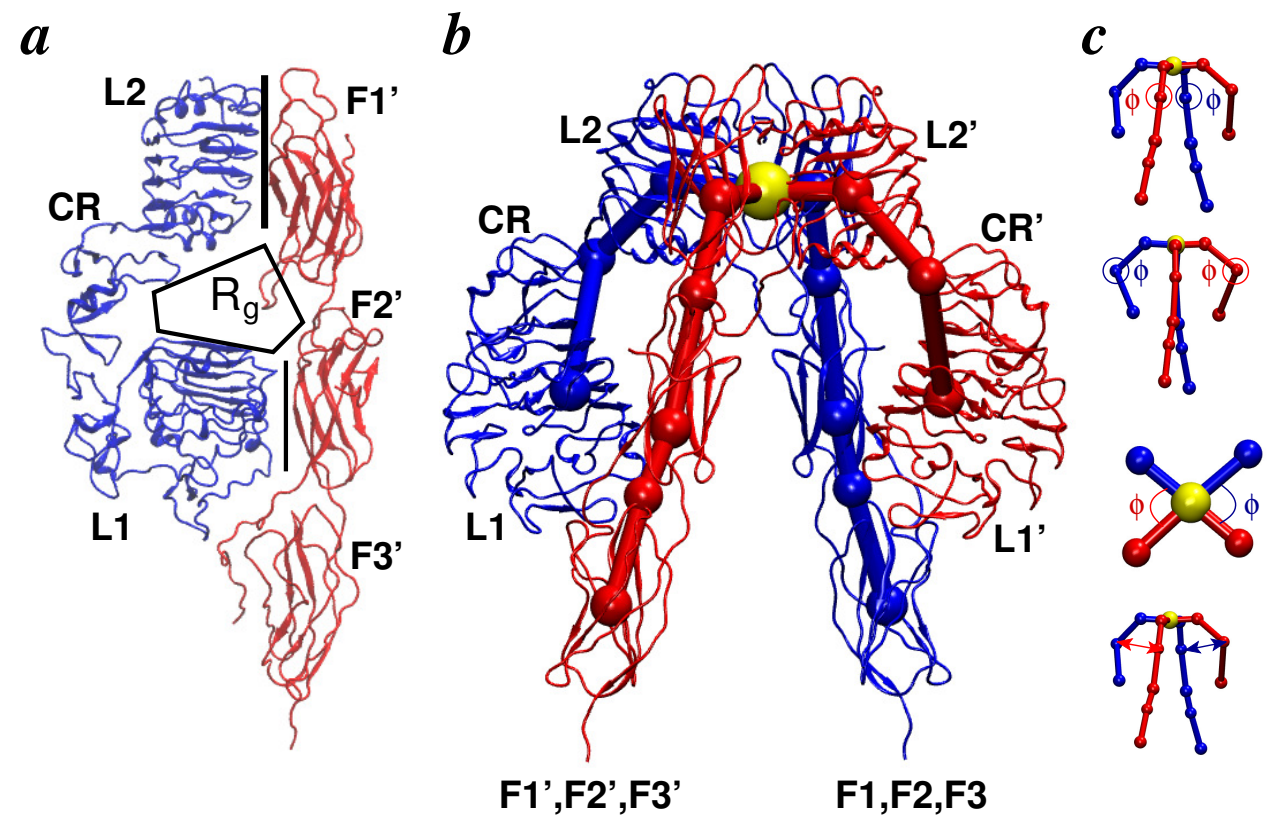

F1',F2',F3'

F1,F2,F3

Figure 4. Conformational metrics of receptors. (a) Schematic illustration of a side view of the IR ectodomain. The binding pocket (indicated by $\mathrm{R}_{\mathrm{g}}$ ) is formed by the L1-CR-L2 motif of one subunit (blue) and the F1-F2-F3 motif of the other subunit (red). The L2-F1' and L1-F2' interfaces are indicated by vertical lines; line thickness indicates higher/lower buried surface area; (b) Overlay of mapping points on the crystallographic conformation of the IR ectodomain. Each subunit is conceptualized as a linear chain of eight mapping points (indicated by spheres) with an additional mapping point (yellow sphere) joining both subunits at the apex. Each mapping point corresponds to either the center-of-mass of a domain or an interdomain hinge; (c) Hinge angles (F1-F2, L1-L2 and L2-F1) are indicated (top), and the interhinge distances between the L1-L2 and F1-F2 hinge points are also shown (bottom).

\subsection{Ligand/Receptor Interactions}

A series of experimental studies on IR [2,49,75,80,85,113-137] and IGF1R [59,138-168] systems have revealed that ligands and receptors interact via two surfaces known as "site 1" and "site 2". Both chains of insulin contribute residues to each site, and similarly, residues in different domains of IGFs are part of each site. Specifically, site 1 on each ligand is comprised of the following residues: G1, I2, V3, Q5, T8, Y19, N21 (insulin A chain); V12, Y16, F24, F25, Y26 (insulin B chain); A8, V11, F23, F24, Y31, R36, R37, V44, A62 (IGF1); and V14, Q18, F26, F28, Y27, S29, S33, V43, F48 (IGF2). Site 2 on each ligand has the following residues: S12, L13, E17 (insulin A chain); H10, E13, L17, V18 (insulin B chain); E9, D12, F16, R21, D53, L54, R56, M59, E58, Y60, K65, K68 (IGF1); and T7, L8, E12, D15, F19, L53, E57 (IGF2). For IR, the site 1 residues (D12, I13, R14, N15, Q34, L36, L37, F39, E44, F64, Y67, F89, N90, Y91, F705, E706, D707, Y708, L709, N711, V712, F714, P716 and R717) are primarily in L1/ $\alpha \mathrm{CT}$, and the site 2 residues (K484, L552, D591, I602, K616, D620 and P621) are in loops of the F1-F2 pair; while for IGF1R, the L1-CR/ $\alpha$ CT motif 
contains site 1 residues (D8, N11, Y28, H30, L32, L33, L56, F58, R59, W79, F90, R240, F241, E242, F251, F692, E693, N694, L696, H697, N698, I700, F701; IGF1 and/or IGF2), and loops of the F1-F2 motif neighboring each binding pocket likely contain site 2 residues (R474, L537, N577, L588, N602, L606, P607; IGF1 and/or IGF2) (Figure 5). Additionally, receptor activation and ligand binding displays allosteric properties, such as high- and low-affinity binding sites, negative cooperativity and ligand dependence of the receptor dissociation rate [84,169-171]. Furthermore, the receptors can bind only a single ligand molecule with high affinity and at least another one with lower affinity [169]. The stoichiometry of insulin binding to the IR ectodomain in the presence of the free CT peptide is known to be 2:2 (insulin:IR subunit) [124,126,130], and small-angle X-ray scattering studies have suggested that between one to three molecules of IGF1 can bind to IGF1R $\Delta \beta$ [73].
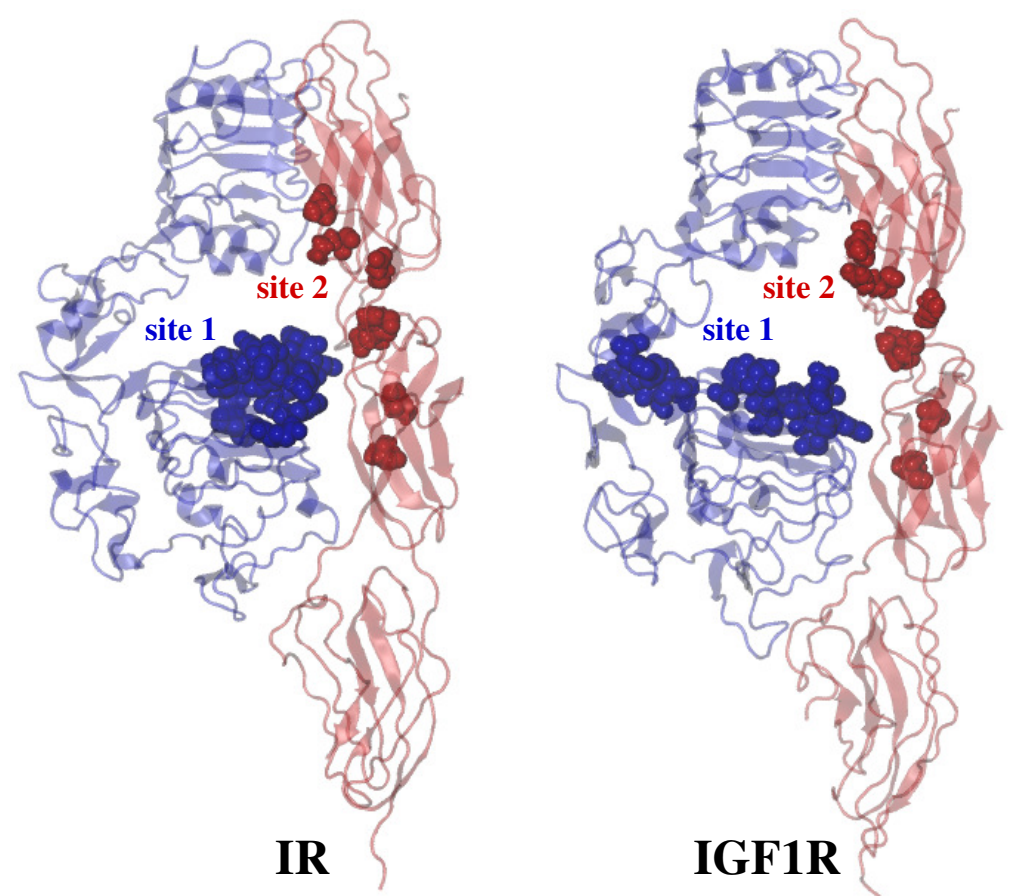

Figure 5. Site 1 and site 2 residues on IR and IGF1R. Schematic illustration of a side view of IR and IGF1R ectodomains indicating site 1 (blue) and site 2 (red) residues in space-filling representations; see Figure 4a for domain labels and the coloring scheme. Site 2 residues are located in the F1-F2 motif of each receptor, while site 1 residues span the L1 (IR) and L1-CR (IGF1R) domains.

\section{Modeling and Simulation Techniques}

Two fundamentally different molecular simulation techniques to study complex (multi-atom) biological systems are molecular dynamics (MD) simulation and Monte Carlo (MC) simulation [172-175]. Both techniques have been used in various studies of ligands and/or receptors of the insulin family, and therefore, in the following, we briefly review the basics of MD and MC simulations. 


\subsection{Molecular Dynamics Simulations}

MD simulation is an approach to compute the time evolution of individual particles (or atoms) interacting under the influence of an interatomic potential function (also known as a force-field) by numerical integration of Newton's equations of motion [176-178]. The state of a system of $N$ particles in a volume $V$ in MD is specified by providing Cartesian coordinates of all particles and corresponding values of initial velocities. The biomolecular force-fields often explicitly account for all bonded (arising from bond-stretching, angle-bending and torsional interactions) and non-bonded forces (arising from van der Waals and electrostatic interactions). Among others, a popular time-tested interatomic potential function for proteins is CHARMM (Chemistry at Harvard Macromolecular Mechanics) $[179,180]$.

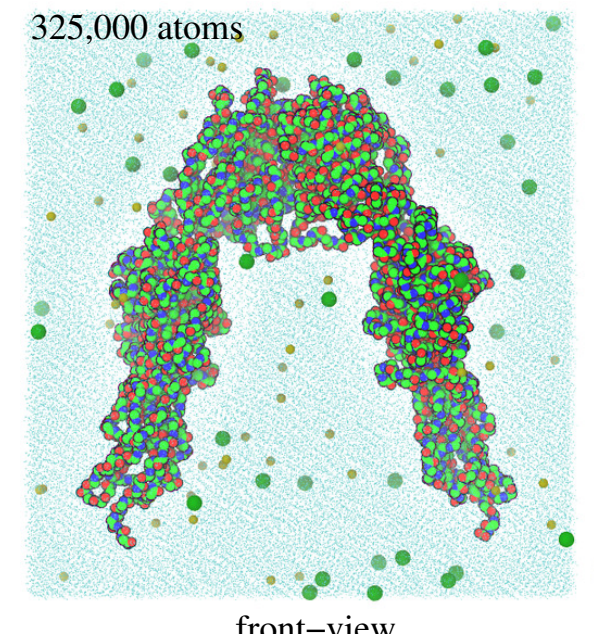

front-view

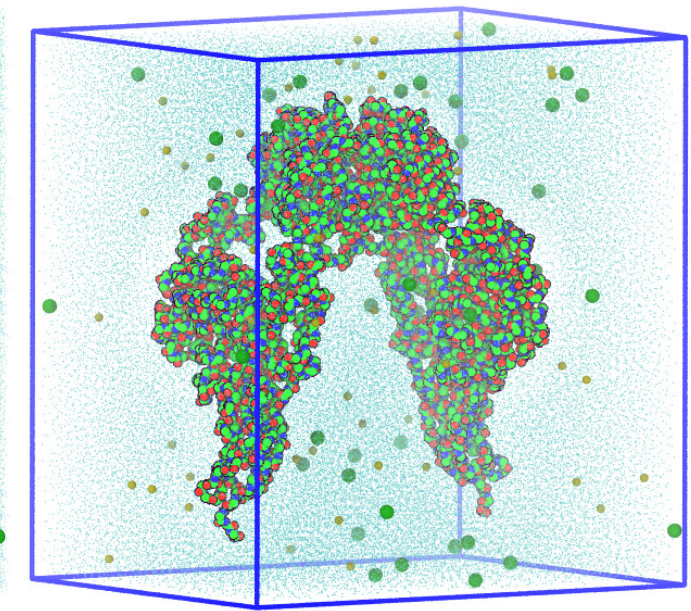

side-view

Figure 6. MD simulation domain. Front and side views of solvated and ionized IGF1R $\Delta \beta$ are shown. The simulation domain measures $158 \times 170 \times 126 \AA^{3}$ and contains $\sim 325,000$ atoms. Protein, ion and water molecules are shown in space-filling, spherical and wireframe representations, respectively.

An MD simulation begins with an initial configuration of the biomolecule, the atomic positions for which are typically extracted from the experimental structures deposited in repositories, such as the Protein Data Bank (PDB) (www.rcsb.org). The PDB structures may contain high-energy interactions due to atomic overlaps, which need to be removed by an energy minimization procedure before beginning the dynamics. The initial configurations are further solvated with explicit water, and counterions are added for maintaining the overall charge neutrality of the system. Hence, the final simulation system may contain thousands of atoms (Figure 6), including those of protein, solvent, ions and small molecules, if any. The initial velocities of all particles are randomly assigned from a Maxwell-Boltzmann distribution at a specified temperature (often $\sim 300 \mathrm{~K}$ ). The temperature and pressure control in MD simulations is achieved by various schemes that implement an algorithm for a thermostat or a barostat [181-185]. Additionally, periodic boundary conditions are applied by replicating the central unit cell to infinity in all directions; in three dimensions, each unit cell will have 26 nearest neighbors. Many simulation packages, such as NAMD (Nanoscale Molecular Dynamics) are now freely available (for academic users) to carry out MD simulations of biomolecules [186,187]. Visualization and analysis of resulting simulation 
trajectories can be done with software packages, such as VMD (Visual Molecular Dynamics) [188]. The quality of the initial model, the degree of sampling and the accuracy of the force-field are a few key factors determining the success of an MD simulation [189].

\subsection{Monte Carlo Simulations}

MC simulation is a method of random sampling, which means that it can be used to generate newer configurations of a system by randomly changing the initial positions of constituent atoms. Metropolis et al. [190] originally proposed importance sampling using MC simulations as a way to bias the random generation of those configurations that make the most significant contribution to the desired property. Each small random move that displaces an initial configuration is known as a trial move. MC simulations are most commonly used for docking calculations in biomolecular systems by using translational and orientational displacements as trial moves. The interaction energy of selected atoms or the potential energy of the new configuration can be used as a basis to accept or reject moves using a Boltzmann factor weighting scheme. In the insulin family, MC simulations have been primarily used for docking ligands into binding pockets of receptors with trial moves comprising rigid-body translational/orientational displacements and configurational sampling of ligands/receptors from pre-equilibrated trajectories to account for biomolecular flexibility [111,112,191].

\subsection{Enhanced Sampling and Free Energy Methods}

Given the many degrees-of-freedom in biomolecules and a small numerical integration time-step ( $\sim$-fs) in MD simulations, it is often not possible to generate long enough trajectories that can capture large-scale and barrier-mediated conformational changes in biomolecules. Therefore, many new simulation techniques based on MD have been devised to increase the likelihood of the observation of such rare events. These "enhanced sampling" methods often explore phase space in reduced collective coordinates (e.g., angles, distances, etc.) and, thereby, are suitable for exploring long time-scale phenomena. In the following, we briefly describe two such techniques, temperature-accelerated molecular dynamics (TAMD) and the string method in collective variables (CVs), which have been jointly used to study conformational changes in the $\mathrm{C}$-terminus of the insulin $\mathrm{B}$ chain and in the activation loop of the IR kinase domain [191,192]. For more details on enhanced sampling techniques, we refer interested readers to recent reviews $[193,194]$.

\subsubsection{Temperature-Accelerated Molecular Dynamics}

Temperature-accelerated molecular dynamics (TAMD) is an enhanced sampling approach to explore the physical free-energy landscape in a large set of CVs [195-202]; CVs here are functions of atomic Cartesian positions. In TAMD, additional auxiliary variables are harmonically coupled to CVs, assigned a fictitious mass and a temperature different from that of the physical system. Furthermore, slower evolution of auxiliary variables is guaranteed by using a higher Langevin friction coefficient on these variables. Due to coupling with the atomistic system, sufficiently high temperature on fictitious variables therefore leads to enhanced sampling of the physical free-energy landscape. For 
generating conformational changes in the C-terminus of the insulin B chain and the kinase domain loop, Cartesian coordinates of centers of mass of spatially contiguous groups of residues were used as CVs in combination with fictitious thermal energies of 5-6 kcal/mol [191,192].

\subsubsection{String Method in Collective Variables}

Given that TAMD only explores the underlying free-energy landscape without actually reconstructing it, other techniques, such as the string method in CVs [203], are needed to quantify free-energy differences between states visited by TAMD [191,192]. By iterative refinement of an initial pathway (such as those generated via TAMD), the string method allows computation of a minimum free-energy path (MFEP). The initial "string" in this technique is a collection of discrete configurations (images) of the molecular system that can be independently simulated to get estimates of mean forces on CVs and, thereby, free-energy as a function of those CVs.

\section{Applications}

Several decades of investigations using biochemical, biophysical and structural studies (vide supra) have provided key insights into the structure-function relationships in the insulin family, yet the dynamics of ligands and receptors remain poorly understood at the molecular level. The main questions about ligands relate to conformational changes in the termini of the insulin B chain, interactions among insulin monomers in oligomeric (dimeric and hexameric) states, stabilization of $\mathbf{R}_{6}$ hexamers via phenolic species, the contribution of the C- and D-domain of each IGF in ligand binding, etc. For receptors, major questions relate to subtle conformational changes in the quaternary structures that lead to: (1) "negative-cooperativity" in ligand binding; (2) low- and high-affinity ligand-bound states; (3) differing affinities of insulin and IGFs for IR/IGF1R; and (4) activation of intracellular kinase domains. Not all of these questions have been answered so far, but a limited number of computational studies that we discuss below have shed light on certain aspects of the conformational dynamics of ligands and receptors.

\subsection{Ligands}

Three different forms of insulin (monomer, dimer and hexamer) have been studied using vacuum and explicit-solvent MD simulations so far. During the emergence of the biomolecular simulation field [204], insulin played an important role as a test system on which a force-field with explicit hydrogens was tested by Wodak et al. [205]. They concluded that the choice of force-field may be at least as important as including solvent molecules in the simulations of proteins. Further vacuum MD studies recommended that solvent simulations are needed to better understand the solution conformations of insulin [206]. Soon after, explicit-solvent simulations of the insulin monomer and dimer demonstrated considerable flexibility in insulin structures that was suggested to reduce the propensity of insulin to form hexamers without divalent cations [207]. Despite earlier suggestions on the importance of solvent molecules, further studies in vacuum on cross-linked insulin monomers were carried out and justified as acceptable [208]. Tidor and Karplus computed the dimerization free energy of insulin as $\sim-7.2 \mathrm{kcal} / \mathrm{mol}$ [209]. The insulin dimer was further studied using 600 ps-long explicit-solvent 
simulations, which showed asymmetry among insulin monomers in the dimer [210]. The insulin monomer was exposed to chemical (disulfide-reduction) and thermal (high-temperature) stress with a focus on the unfolding behavior of the B chain $\alpha$-helix [211]. This study showed that chemical stress alone results in smaller conformational changes consistent with experimental observations. A significant explicit-solvent MD study of monomeric and dimeric insulins suggested increased flexibility in the termini of the insulin B chain, separation of the C-terminus of the insulin B chain that exposes receptor binding residues in the A chain and the role of mutation at residue B24 (Phe $\rightarrow$ Gly) in inducing greater flexibility in the C-terminus of the insulin B chain [212]. Force-induced dissociation of the insulin dimer using steered MD simulations [213] suggested that the dissociation pathway depends on the relative strength of the inter-monomer interactions across the antiparallel $\beta$-sheet interface [214]. Residues contributing to the stability of the insulin monomer were also probed with computational alanine scanning in the same spirit as the experimental alanine scanning mutagenesis approach [215]. The excised insulin B chain was further extensively scrutinized by two different MD studies [216,217]. Particularly, high-temperature studies demonstrated flexibility in the termini of the insulin B chain and suggested the role of Gly ${ }^{\mathrm{B} 8}$ as a helix-breaker residue leading to T-like conformations of the insulin B chain [216], while the bias-exchange metadynamics study revealed three metastable basins separated by a large free-energy barrier, including a folded-state basin with a transformed and separated C-terminus of the insulin B chain [217]. A novel simulation method, known as targeted MD (TMD), was also applied to the insulin monomer, as well as the hexamer for studying the $\mathbf{T} \rightarrow \mathbf{R}$ transition [218,219]. Motivated by earlier studies on protein hydration [220,221], a study on water dynamics at the dimer forming surface (DFS) and hexamer forming surface (HFS) of insulin revealed that more structured water molecules with higher residence times were present at HFS in comparison to those at DFS [222].

Taking the insulin hexamer as an example for understanding the binding/dissociation of small molecules, two different studies [223,224] have attempted to explore phenol dissociation pathways from hydrophobic binding pockets of the $\mathbf{R}_{6}$ insulin hexamer (see Figure 2). Swegat et al. [224] found one dissociation mechanism for a phenolic ligand, while Vashisth and Abrams [223] reported multiple phenol binding/unbinding routes. The latter study computed the potentials of mean force (PMFs) for three-different phenol dissociation pathways and found two competing mechanisms namely "gate-opening" and "gate-leaping" (Figure 7). Although insulin has been investigated in many studies described above, no detailed molecular simulation studies on IGFs have been reported so far (to the best of our knowledge). 

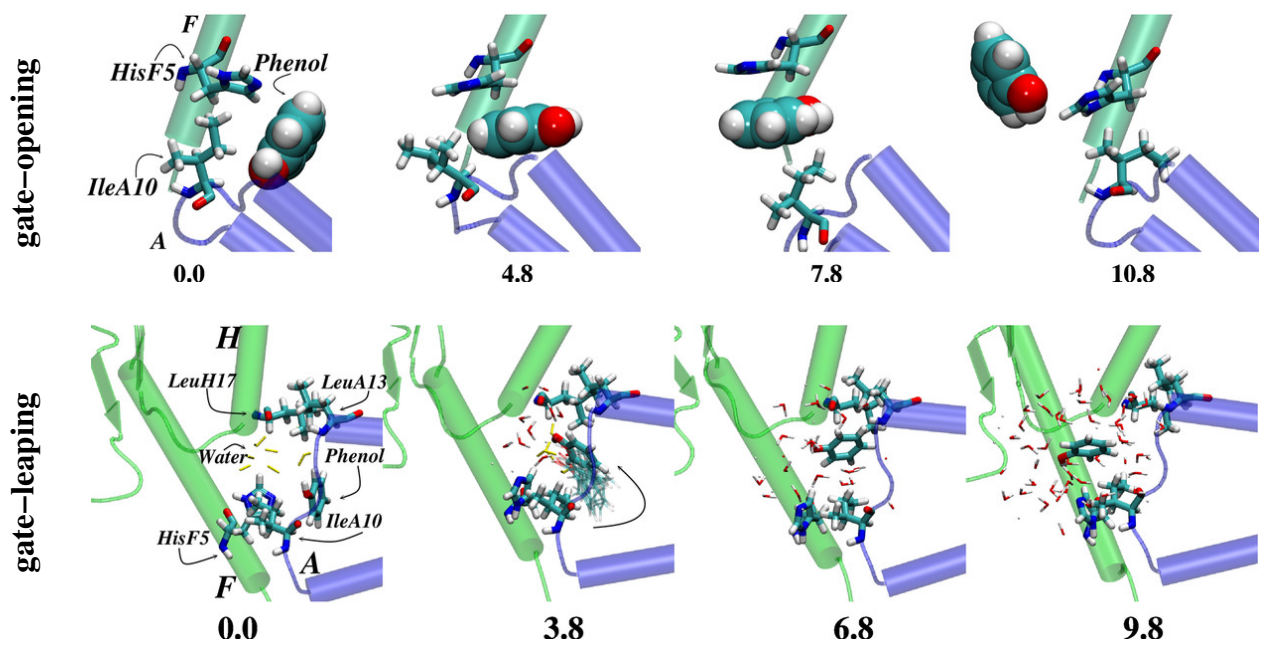

Figure 7. Gate-opening vs. gate-leaping mechanisms. Top-view and side-view snapshots for two different phenol dissociation mechanisms, gate-opening and gate-leaping, respectively. The numbers at the bottom of the panels show distances along the dissociation reaction coordinates. Additionally, two key gatekeeper residues, $\mathrm{His}^{\mathrm{F} 5}$ (B chain) and $\mathrm{Ile}^{\mathrm{A} 10}$ (A chain), are shown in sticks and labeled. Panels adapted with permission from [223].

\subsection{Receptors}

Vashisth and Abrams have carried out three different simulation studies on apo and ligand-bound $\operatorname{IR} \Delta \beta$ and IGF1R $\Delta \beta$ [111,112,191] and one study on the insulin receptor kinase domain [192]. Additionally, a new structural model of the insulin/IR complex based upon an earlier structural model [191] has been reported [225]. In the following, we describe key findings, as well as the limitations of these studies.

\subsubsection{Apo Ectodomains}

Earlier experimental work has suggested the presence of low- and high-affinity ligand binding sites and/or "negative-cooperativity" in IR and IGF1R [170,171]. These observations were initially rationalized by Schäffer [226] in a cross-linking model in which a single ligand molecule can bridge two distinct binding sites on receptors. In the same year, De Meyts [84] proposed a better model by postulating that receptor dimers would have internal symmetry, such that site 1 on one subunit is positioned near site 2 of the other subunit (later found to be true), thereby allowing high-affinity ligand binding in one pocket and low-affinity in the other. Based on structural evidence, McKern et al. [71] proposed a "see-saw" mechanism of negative-cooperativity consistent with De Meyts' model [2,49,84]. In this mechanism, the receptor ectodomain can rock back and forth between symmetry-inverted states driven by insulin binding. However, the most recent "harmonic-oscillator" model by De Meyts and colleagues [169] suggests that small thermal energies can drive the apo-ectodomains of receptors between symmetry-inverted asymmetric states potentially capable of binding ligands. Large-scale atomistic simulations of receptor ectodomains have revealed that both $\operatorname{IR} \Delta \beta$ and IGF1R $\Delta \beta$ exhibit spontaneous asymmetric mechanisms of flexibility that directly provide evidence in favor of the 
harmonic-oscillator model. Such asymmetry can also be indirectly inferred from ectodomain structures, because intact crystal conformations of ligands cannot be docked [70,71] in binding pockets of receptors without significant steric overlaps. As described below, the flexibility and asymmetry in apo-ectodomains is observed at different levels in MD simulations [111,112].

Intradomain flexibility analyses from simulations suggest that: (1) the overall fold of all domains is relatively preserved in solution; (2) the CR domain and fibronectin repeats are intrinsically more flexible than L1 and L2; and (3) the N-terminal loops of CR in IR (junction of CR and L1) and the C-terminal loops of CR in IGF1R (junction of CR and L2) show increased flexibility. Interdomain and intersubunit flexibility in ectodomains can be evaluated by various geometric measures (see Section 2.2.1 and Figure 4) that characterize the relative movement of domains, the size of binding pockets and the integrity of domain interfaces. These measures have collectively suggested that closing of the F1-F2 hinge on one side of the receptor dimer moves the hinge point away from the nearest L1-L2 hinge, such that the associated L2/F1 interface opens slightly (manifest also as an increase in the apical L2-F1 hinge-angle). This in combination with the closing of the L1-L2 hinge further leads to one binding pocket being more open than the other. Therefore, the receptor dimer is locked in a state where the apical L2-F1 hinge angle, as well as the L2/F1 interface on the closed-pocket side of dimer is more intact than the open-pocket side. A large enough fluctuation can then drive the structural transition in the opposite direction, given that the F1-F2 hinge on the closed side also experiences fluctuation, leading to its movement away from the L1-L2 hinge. This way, random thermal fluctuations in interdomain hinge angles can lead to spontaneous asymmetry in the intersubunit interfaces, as well as binding pockets. This would also mean that the intersubunit interfaces (L1/F2 and L2/F1) in symmetric receptor dimers (Figure 3) are not at their optimum strength. Interestingly, independent simulations of ectodomains also found that each pocket has equal probability of opening/closing, because the same pocket could be observed at least once either in the open or closed state. Moreover, it is observed that the change in size of each binding pocket is slower than that of the interfacial areas, but matches the rate of change of hinges. Importantly, these interdomain flexibility mechanisms validate the prediction of McKern et al. [71] that domain movements potentially occur at the CR-L2, L2-F1 and F1-F2 junctions.

Given that the F1-F2 hinges can spontaneously close, thereby leading to asymmetric features in receptors, it was speculated that the symmetric crystallization of apo-IR $\Delta \beta$ likely occurred due to the binding of antibody fragments, in particular 83-14, which binds specifically to $F 1$ near the F1-F2 hinge [111]. This is also consistent with the finding that 83-14 binding to IR inhibits insulin binding [227], likely because it prevents closing of the F1-F2 hinge angle, which is required to create an open pocket for insulin binding. Asymmetry in receptors was further validated by the fact that solution conformational ensembles of apo-IGF1R $\Delta \beta$ probed by SAXS experiments [73] and MD simulations [112] matched well. Simulations of apo-IR $\Delta \beta$ showed that asymmetry can also exist in various salt bridges located in the intersubunit interfaces [111]: Lys $^{460}$ can participate in an intradomain salt bridge with $\mathrm{Asp}^{464}$ or in an interdomain salt bridge with $\mathrm{Asp}^{574}$. If the intersubunit salt bridge helps the tightening of the L2/F1 interface while the intrasubunit bridge frustrates the interface, this would suggest a crucial role for Lys ${ }^{460}$, consistent with mutational studies [228]. 


\subsubsection{Ligand/Receptor Complexes}

A major consequence of asymmetry in the binding pockets is that the intact ligands (insulin/IGFs) could be successfully docked in the open pockets (Figure 8) of their cognate receptors (but not in the closed pockets). All-atom structural models of ligand/receptor complexes [111,112,191,225] constructed using MC-docking calculations and MD-equilibrated thereafter were the first physically plausible complex structures based on which many experimental observations could be rationalized. The ligand/receptor complexes showed that a single ligand in the binding pocket can simultaneously contact site 1 and site 2 residues on the receptor. This is consistent with experimental observations that ligands can cross-link receptor subunits [229,230], because in all-atom structural models, each ligand contacts at least one domain of the L1-CR-L2 motif of one subunit and the F1-F2 motif of the other subunit (Figure 8). The structural models also predicted many site 2 contacts between ligands and receptors out of which site 2 residues on IR appear consistent with bioinformatics analysis [137] and mutagenesis work [131], and site 2 residues of IGF1R [112] remain testable predictions. Specifically, insulin residues (1) A12, A13, A14, A15, A17 were observed in contact with F1 residues R554, G555, L556, K557 and Y562, (2) A10 and B18 were observed in contact with F1 residues Y507 and K484, respectively; and (3) B10 and B13 were observed in the vicinity of F2 residues S596, L599, D620 and P621 [225]. Earlier structural models of insulin/IR complexes without CT peptide [111] suggested sustained contacts between insulin residues A13, A17 and B17 and receptor residues K484 and L552 (F1). A mutagenesis study by Whittaker et al. [131] listed K484 and L552 among the five most important residues for insulin binding in the F1-F2 motif of IR. For site 2 contacts in the IGFs/IGF1R system, all-atom structural models [112] have suggested contacts of ligand residues E9, D12, F16, D53, L54 and E58 (IGF1) and E12, D15, F19, L53 and L57 (IGF2) with IGF1R residues N473, R474, Y496, W519, N520, M521, V522, D523, L526, P528, L537, L538, H539, G540, L541, K542, Y547, V580, S582, I583, L585, L606, P607 and N608. Importantly, all IGF1/2 residues listed above were suggested as site 2 contacts by two major mutagenesis efforts $[159,160]$.

It is known that insulin can bind only with low affinity to IR $\Delta \beta$ unless $\beta$-subunits are membrane-embedded or fused to dimerizing proteins [166,231,232], while IGFs can bind with high affinity to both free or leg-restricted IGF1R $\Delta \beta$ [233]. This observation in combination with studies on hybrid IGF1R/IR chimeras [136,234] possessing high affinity for IGFs has led to the possibility that the increased affinity of IGFs may be due to the presence of two additional domains ( $\mathrm{C}$ and D), unlike insulin (Figure 1). Simulations provided strong evidence in favor of this view, because extensive additional contacts between the C- and D-domains of IGFs and the loops of the CR and L2 domains were observed [112]. Specifically, in all-atom structural models, R36 and R37 (IGF1) interact with IGF1R residues E242, E264 and E276, and IGF2 residues R37 and R38 interact with IGF1R residues E264 and E276. Furthermore, a stable salt-bridge between R37 (IGF1) and E264 (IGF1R) was observed in simulations [112]. These contacts were further consistent with earlier studies that probed the importance of additional domains in IGFs' binding [138,141,143,148,153,167,168,235-238] and suggested electrostatic complementarity between the C-domain and a CR loop (253-266) of IGF1R [70,239]. Another important issue related to ligand recognition by receptors is the interplay of a tandem hormone binding element, the $\alpha \mathrm{CT}$ peptide (Figure 3), and the B chain of insulin or B/C domains 
of IGFs. Several photo-crosslinking and mutational experiments in combination with observations on insulin mimetic peptides [72,119,128,240-245] have suggested that $\alpha \mathrm{CT}$ is potentially mobile and may be displaced upon ligand binding. Thermodynamic calculations on all-atom insulin/IR $\Delta \beta$ models constructed with $\alpha \mathrm{CT}$ in its crystallographic position and a displaced position [191] strongly suggested the displacement of $\alpha \mathrm{CT}$ on insulin binding, also finally confirmed in crystal structures [76,77]. The displaced- $\alpha$ CT models [191,225] also suggested a previously known conformational change in the C-terminus of the insulin B chain [246-249] that exposes (to site 1 on IR) residues hidden in the hydrophobic core of insulin. Importantly, the comparison between insulin-bound and apo crystal structures of IR have suggested that hormone conformation in insulin-bound structures cannot be accommodated in the apo-IR ectodomain, due to the steric overlap [76,91] of insulin with the F1-F2 motif. Therefore, the displacement of the F1-F2 pair has been suggested upon insulin binding [91]. A recent all-atom structural model of the insulin/IR $\Delta \beta$ complex [225] has provided evidence in support of this view, because closing of the F1-F2 hinge leads to a displaced conformation of the F1-F2 motif that facilitates insulin binding without steric overlap.
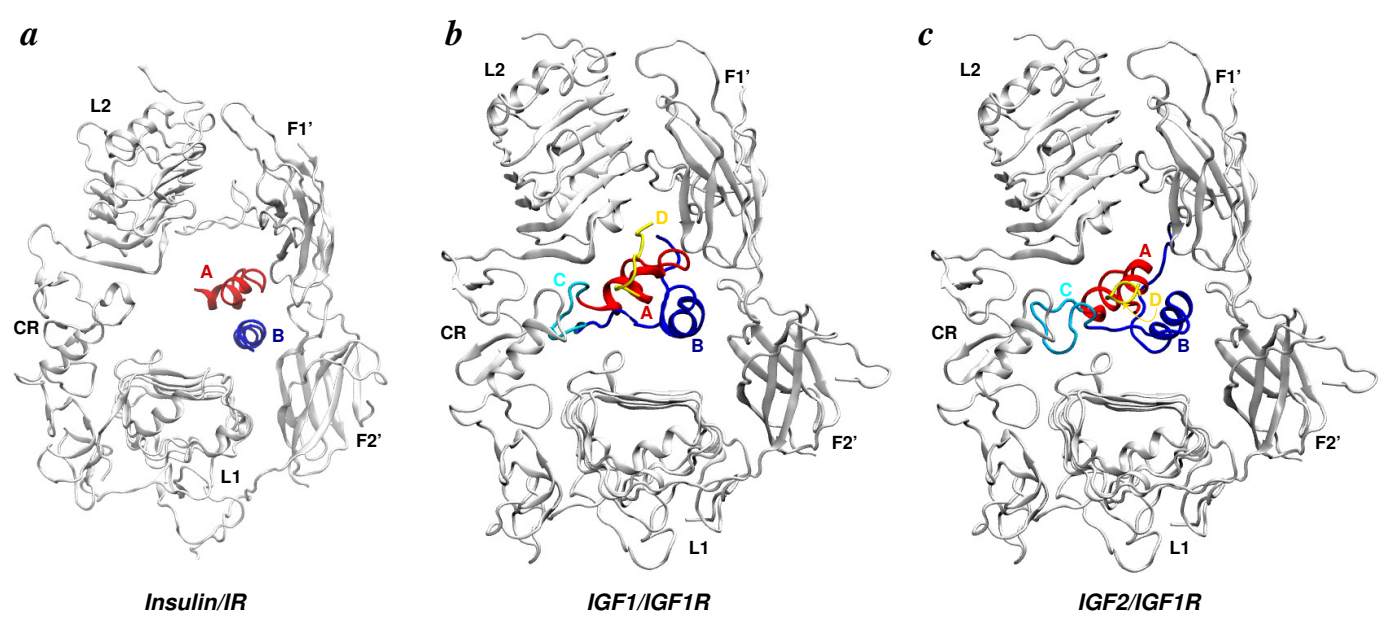

Figure 8. Docked conformations of insulin and IGFs. Docked views of each ligand in the relatively open binding pocket (formed by the L1-CR-L2 motif of one subunit and the F1-F2 motif of the other subunit) are shown. Both chains of insulin and four domains of each IGF are distinctly colored and labeled. (a) Based on the ligand/receptor complex reported in [225]; (b,c) based on ligand/receptor complexes reported in [112]; (b) and (c) adapted with permission from [112].

\subsubsection{Intracellular Kinase Domains}

As pointed out earlier, binding of ligands to receptor ectodomains leads to the activation of intracellular kinase domains. Although it is not well understood at the structural level how a ligand transmits the signal across the membrane, it is known that the activation of kinase modules in receptors occurs via trans-autophosphorylation of three tyrosine residues situated in the activation loop (A-loop) [250,251]. 

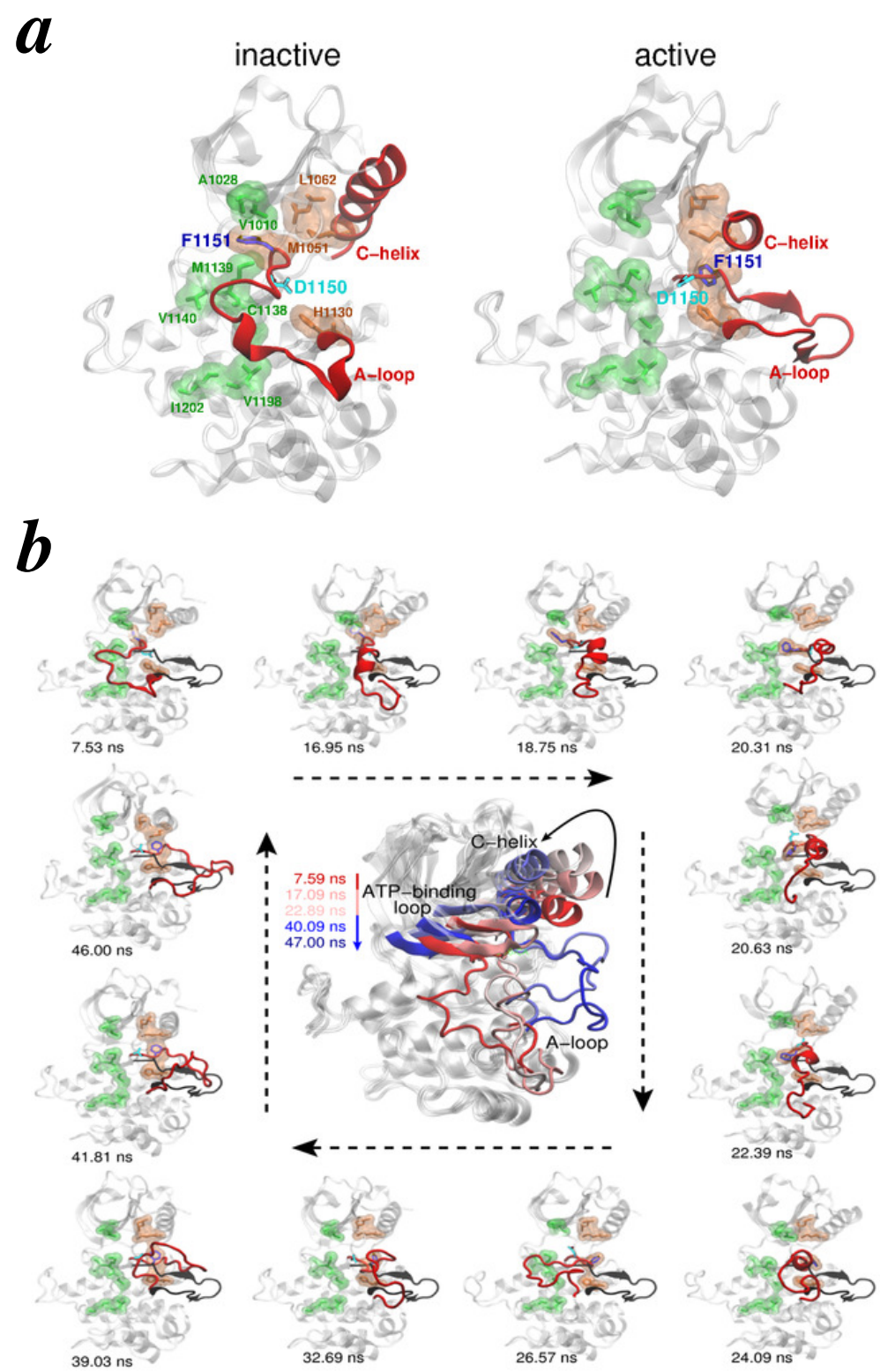

Figure 9. Kinase conformational change. (a) Key structural differences in the inactive (PBD Code 1IRK) and active kinase (PDB Code 1IR3) crystal structures are highlighted and labeled. The A-loop and $\alpha \mathrm{C}$-helix are shown as red cartoons, and residues of $\mathrm{R}$-spine and C-spine are shown as brown and green sticks/surfaces, respectively, and labeled; (b) Snapshots of the kinase domain are depicted during temperature-accelerated molecular dynamics (TAMD)-generated conformational change in the A-loop. Conformation of the A-loop in the active crystal structure is also overlayed (black cartoon). Panels adapted with permission from [192].

Many structural studies on IR and IGF1R have revealed that during activation, a large conformational change involving displacement (by $\sim 20 \AA$ ) of the A-loop occurs [64-67]. The conformational change in the A-loop is further coupled with rotation (by $\sim 30^{\circ}$ ) of the $\alpha$-helix in the N-lobe and the flip of an Asp(D)/Phe(F) pair in the conserved Asp-Phe-Gly (DFG) motif. Furthermore, these structural changes result in the proper placement of a network of residues collectively known as the regulatory (R) and 
catalytic (C) spine [252-254] (Figure 9a). Molecular simulations have previously provided insights into the structural transitions underlying the activation of other kinases [255-259].

Similarly, Vashisth and Abrams studied the conformational change in the A-loop of the IR kinase domain using TAMD simulations and the string method in CVs (see Section 3.3 for details on the methods) [192]. TAMD simulations in this work showed consistent folding of the A-loop into helical intermediate conformations that result in the flip of the DFG-motif, primarily due to changes in backbone dihedrals (Figure 9b). Detailed free-energy calculations further supported these conclusions, as the metastable helical conformations predicted by TAMD were observed to exist along the characterized minimum free energy path (MFEP). The analysis of the structural changes also revealed that the R-spine can be dynamically assembled or disassembled via the DFG-flip or the rotation of the $\alpha$-helix in the $\mathrm{N}$-lobe. In this study, an isolated kinase domain was studied in absence of ATP, and therefore, it was unclear how inter-kinase contacts or the presence of nucleotide may affect the activation pathway.

\subsection{Limitations of Modeling Studies}

Though molecular simulations have provided significant insights into the dynamics of the ligands and receptors of the insulin family, certain limitations of these modeling studies bear mentioning. Some of these include the absence of unresolved residues in the insert domain (ID) and the absence of Fab/Mab antibody fragments, as well as glycans. Moreover, simulations of IGF1R were based on a homology model that did not include $\alpha \mathrm{CT}$, an essential ligand binding element. The missing structural elements therefore make it difficult to attribute models to low-affinity or high-affinity complexes. The models also suggest that a bound ligand on one side of the receptor dimer may help in the opening of the binding pocket on the unoccupied side, which may allow the binding of at least another ligand. However, this has not been directly demonstrated yet, and therefore, suggestions about the stoichiometry in ligand/receptor binding may be speculative. Additionally, the reasons for the discrepancies between the theoretical vs. experimental scattering profiles of the solution ensembles of the IGF1/IGF1R $\Delta \beta$ complex were not apparent [112]. It is also important to point out that none of the aforementioned simulation studies of the receptors included the membrane environment, and hence, it is not obvious how the conformational changes are conveyed to the intracellular kinase domains. Lastly, due to large system sizes, simulations only explored the conformational dynamics under a $\sim 100$-ns timescale, and therefore, the conformational changes occurring on longer timescales, if any, may not have been captured in these trajectories.

\section{Outlook}

In this work, we have reviewed applications of various molecular simulation techniques to ligands and receptors of the insulin family. We have focused on key questions relating to the conformational dynamics of ligands and receptors that can be suitably probed with large-scale simulations. Particularly, simulations have highlighted plasticity in ligands, as well as receptors that is potentially exploited in their productive binding. All-atom models of complexes suggest ligand cross-linking of receptor subunits and hint at the determinants of ligand specificity for their cognate receptors, an example of which is the interaction between the C-domain of IGFs with loops in the CR domain of IGF1R. Though 
not mentioned in the discussion above, analyses of the flexibility of membrane-proximal domains of receptors in apo- and ligand-bound forms suggest (Table S2 in [191]) that soluble apo-ectodomains display an equal probability of the opening/closing of receptor legs, but binding of ligands seems to stabilize the legs of soluble ectodomains, such that the distances between legs either decrease by $\sim 3-5 \AA$ or stay near values in symmetric structures. One can therefore speculate that a decrease in the distance of receptor legs can be further stabilized in the presence of membrane anchors. Interestingly, it has been observed earlier that insulin binding to membrane-anchored IR leads to compaction of the entire complex [260], as schematically shown in Figure 10a. However, two recent studies [261,262] have suggested different mechanisms [263] of IR and IGF1R activation. Kavran et al. [261] probed IGF1 binding to IGF1R and showed that ligand binding disrupts the L1-F2' interface (see Figure 4a), leads to dimerization of transmembrane helices and trans-phosphorylation in kinase domains. Lee et al. [262] have shown in the insulin/IR system that constitutively dimerized transmembrane helices instead dissociate from one another on activation. These studies highlight the importance of further understanding helix dimerization/dissociation, juxtamembrane regions and other steric constraints in receptor activation. To test the role of membrane anchors, future simulation studies of receptors in the presence of membrane are needed. With the availability of structural data on ligands, receptor ectodomains, transmembrane domains and kinase domains, an ambitious goal for future model building studies is to construct a testable all-atom model of the holo-receptor (Figure 10b).

$a$

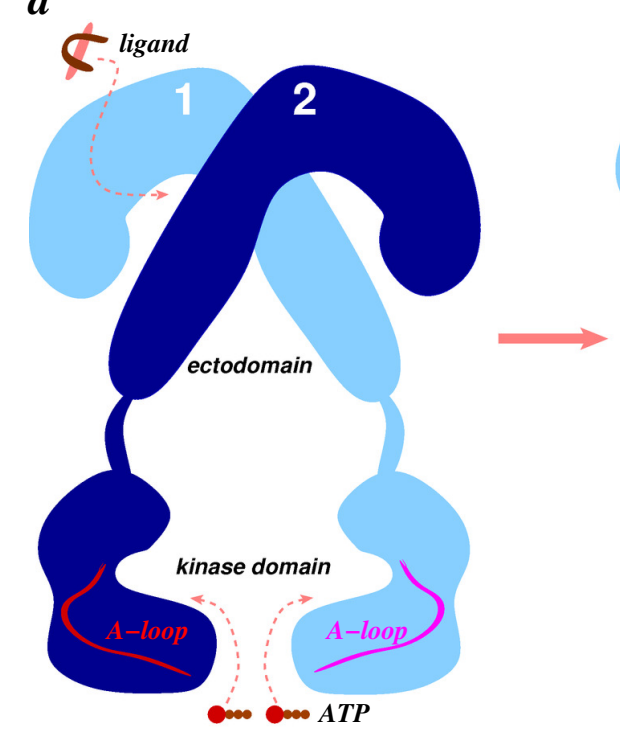

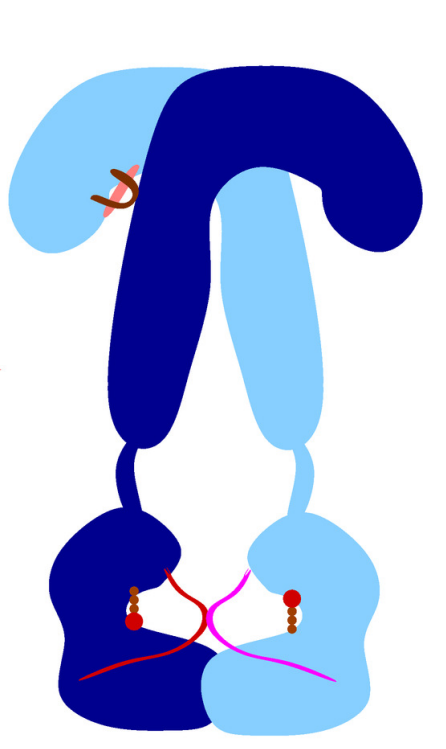

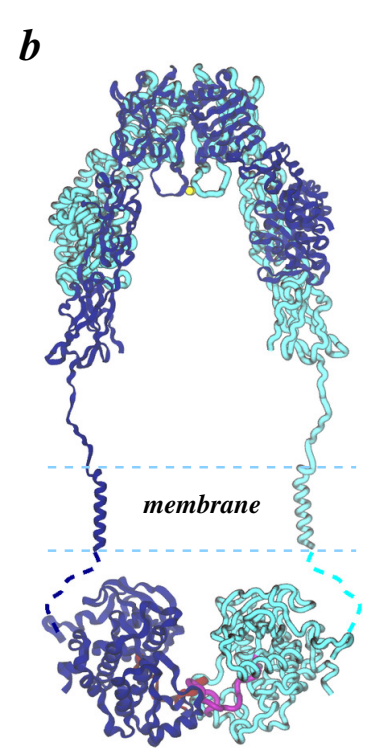

Figure 10. Schematics of the holo-receptor. Ligand-triggered compaction of the entire complex leading to the movement of intracellular kinase domains is shown (a), and a schematic of the entire receptor architecture constructed from known crystal structures of the IR ectodomain and the kinase domain is shown (b). Transmembrane helices in (b) were modeled. The orientation, as well as placement of the kinase dimer, are purely speculative. Missing juxtamembrane regions are shown with dashed lines, and the C-terminal tails are not shown. 


\section{Acknowledgments}

We thank Hossein Mohammadiarani for a critical reading of the manuscript and acknowledge seed funding from the University of New Hampshire.

\section{Conflicts of Interest}

The author declares no conflicts of interest.

\section{References}

1. Heller, S.; Kozlovski, P.; Kurtzhals, P. Insulin's 85th anniversary-An enduring medical miracle. Diabetes Res. Clin. Pract. 2007, 78, 149-158.

2. De Meyts, P. Insulin and its receptor: Structure, function and evolution. BioEssays 2004, 26, 1351-1362.

3. Rosenfeld, L. Insulin: Discovery and controversy. Clin. Chem. 2002, 48, 2270-2288.

4. King, K.M. A history of insulin: From discovery to modern alternatives. Br. J. Nurs. 2003, 12, 1137-1141.

5. Ward, C.W.; Lawrence, M.C. Landmarks in insulin research. Front. Endocrin. 2011, 2, 76.

6. Vashisth, H. Molecular simulation studies of the insulin receptor family. Ph.D. Thesis, Drexel University, Philadelphia, PA, USA, 2010.

7. Steiner, D. Adventures with insulin in the Islets of Langerhans. J. Biol. Chem. 2011, 286, 17399-17421.

8. Banting, F.; Best, C.; Collip, J.; Campbell, W.; Fletcher, A. Prancreatic extracts in the treatment of diabetes mellitus. Can. Med. Assoc. J. 1922, 12, 141-146.

9. Banting, F.; Best, C. The internal secretion of the pancreas. J. Lab. Clin. Med. 1922, 7, 251-266.

10. Poulsen, J.E. The impact of August Krogh on the insulin treatment of diabetes and our present status. Acta. Med. Scand. 1975, 578 (Suppl.), 7-14.

11. Scott, D.; Fisher, A. The effect of zinc salts on the action of insulin. J. Pharmacol. Exp. Ther. 1935, 55, 206.

12. Hagedorn, H.; Jensen, B.; Krarup, N.; Wodstrup, I. Portamine Insulinate. J. Am. Med. Assoc. 1936, 106, 177-180.

13. Steiner, D.F.; James, D.E. Cellular and molecular biology of the beta cell. Diabetologia 1992, 35, S41-S48.

14. Yalow, R.S. Radioimmunoassay. Annu. Rev. Biophys. Bioeng. 1980, 9, 327-345.

15. Yalow, R.S. Radioimmunoassay: A probe for fine structure of biologic systems. Scand. J. Immunol. 1992, 35, 4-20.

16. Felig, P. Protamine insulin-Hagedorn's pioneering contribution to drug delivery in the management of diabetes. J. Am. Med. Assoc. 1984, 251, 393-396.

17. Brange, J.; Ribel, U.; Hansen, J.F.; Dodson, G.; Hansen, M.T.; Havelund, S.; Melberg, S.G.; Norris, F.; Norris, K.; Snel, L.; et al. Monomeric insulins obtained by protein engineering and their medical implications. Nature 1988, 333, 679-682. 
18. Pandyarajan, V.; Weiss, M.A. Design of non-standard insulin analogs for the treatment of diabetes mellitus. Curr. Diab. Rep. 2012, 12, 697-704.

19. Bakaysa, D.L.; Radziuk, J.; Havel, H.A.; Brader, M.L.; Li, S.; Dodd, S.W.; Beals, J.M.; Pekar, A.H.; Brems, D.N. Physicochemical basis for the rapid time-action of Lys(B28)Pro(B29)-insulin: Dissociation of a protein-ligand complex. Prot. Sci. 1996, 5, 2521-2531.

20. Birnbaum, D.T.; Kilcomons, M.A.; DeFelippis, M.R.; Beals, J.M. Assembly and dissociation of human insulin and Lys(B28)Pro(B29)-insulin hexamers: A comparison study. Pharm. Res. 1997, $14,25-36$.

21. Lowman, A.M.; Morishita, M.; Kajita, M.; Nagai, T.; Peppas, N.A. Oral delivery of insulin using pH-responsive complexation gels. J. Pharm. Sci. 1999, 88, 933-937.

22. Langer, R.; Peppas, N.A. Advances in biomaterials, drug delivery, and bionanotechnology. AIChE J. 2003, 49, 2990-3006.

23. Foss, A.C.; Goto, T.; Morishita, M.; Peppas, N.A. Development of acrylic-based copolymers for oral insulin delivery. Euro. J. Pharm. Biopharm. 2004, 57, 163-169.

24. Morishita, M.; Lowman, A.M.; Takayama, K.; Nagai, T.; Peppas, N.A. Elucidation of the mechanism of incorporation of insulin in controlled release systems based on complexation polymers. J. Control. Release 2002, 81, 25-32.

25. Mo, R.; Jiang, T.; Di, J.; Tai, W.; Gu, Z. Emerging micro-and nanotechnology based synthetic approaches for insulin delivery. Chem. Soc. Rev. 2014, 43, 3595-3629.

26. Stretton, A.O.W. The first sequence: Fred Sanger and insulin. Genetics 2002, 162, 527-532.

27. Adams, M.J.; Blundell, T.; Dodson, E.; Dodson, G.; Vijayan, M.; Baker, E.; Harding, M.; Hodgkin, D.; Rimmer, B.; Sheat, S. Structure of rhombohedral 2 zinc insulin crystals. Nature 1969, 224, 491-495.

28. Blundell, T.L.; Dodson, G.G.; Hodgkin, D.C.; Mercola, D. Insulin: The structure in the crystal and its reflection in chemistry and biology. Adv. Protein Chem. 1972, 26, 279-402.

29. Bentley, G.A.; Dodson, E.J.; Dodson, G.G.; Hodgkin, D.C.; Mercola, D. Structure of insulin in 4-zinc insulin. Nature 1976, 261, 166-168.

30. Baker, E.N.; Blundell, T.L.; Cutfield, J.F.; Cutfield, S.M.; Dodson, G.G.; Hodgkin, D.M.C.; Hubbard, R.E.; Issacs, M.W.; Reynolds, C.D.; Sakabe, K.; et al. The structure of 2Zn pig insulin crystals at $1.5 \AA$ A resolution. Phil. Tran. Roy. Soc. Ser. B 1988, 319, 369-456.

31. Derewenda, U.; Derewenda, Z.; Dodson, E.J.; Dodson, G.G.; Reynolds, C.D.; Smith, G.D.; Sparks, C.; Sweson, D. Phenol stabilizes more helix in a new symmetrical zinc insulin hexamer. Nature 1989, 338, 594-596.

32. Smith, G.D.; Dodson, G.G. Structure of a rhombohedral $\mathrm{R}_{6}$ insulin/phenol complex. Proteins Struct. Funct. Genet. 1992, 14, 401-408.

33. Smith, G.D.; Ciszak, E.; Pangborn, W. A novel complex of a phenolic derivative with insulin: Structural features related to the $\mathrm{T} \leftrightarrow \mathrm{R}$ transition. Protein Sci. 1996, 5, 1502-1511.

34. Smith, G.D.; Blessing, R.H. Lessons from an aged, dried crystal of $\mathrm{T}_{6}$ human insulin. Acta Crystallogr. D Biol. Crystallogr. 2003, D59, 1384-1394. 
35. Williamson, K.L.; Williams, R.J.P. Conformational analysis by nuclear magnetic resonance: Insulin. Biochemistry 1979, 18, 5966-5972.

36. Chang, X.; Jorgensen, A.M.M.; Bardrum, P.; Led, J.J. Solution structures of the $\mathrm{R}_{6}$ human insulin hexamer. Biochemistry 1997, 36, 9409-9422.

37. O’Donoghue, S.I.; Chang, X.; Abseher, R.; Nilges, M.; Led, J.J. Unraveling the symmetry ambiguity in a hexamer: Calculation of the $\mathrm{R}_{6}$ human insulin structure. J. Biomol. NMR 2000, $16,93-108$.

38. Cooke, R.M.; Harvey, T.S.; Campbell, I.D. Solution structure of human insulin-like growth factor 1: A nuclear magnetic resonance and restrained molecular dynamics study. Biochemistry 1991, 30, 5484-5491.

39. Torres, A.M.; Forbes, B.E.; Aplin, S.E.; Wallace, J.C.; Francise, G.L.; Norton, R.S. Solution structure of human insulin-like growthfactor II. Relationship to receptor and binding protein interactions. J. Mol. Biol. 1995, 248, 385-401.

40. Vajdos, F.F.; Ultsch, M.; Schaffer, M.L.; Deshayes, K.D.; Liu, J.; Skelton, N.J.; de Vos, A.M. Crystal structure of human insulin-like growth factor-1: Detergent binding inhibits binding protein interactions. Biochemistry 2001, 40, 11022-11029.

41. Sato, A.; Nishimura, S.; Ohkubo, T.; Kyogoku, Y.; Koyama, S.; Kobayashi, M.; Yasuda, T.; Kobayashi, Y. Three-dimensional structure of human insulin-like growth factor-I (IGF-I) determined by 1H-NMR and distance geometry. Int. J. Pept. Protein Res. 1993, 41, 433-440.

42. Brzozowski, A.M.; Dodson, E.J.; Dodson, G.G.; Murshudov, G.N.; Verma, C.; Turkenburg, J.P.; de Bree, F.M.; Dauter, Z. Structural origins of the functional divergence of human insulin-like growth factor-I and insulin. Biochemistry 2002, 41, 9389-9397.

43. Cuatrecasas, P. Insulin-receptor interactions in adipose tissue cells: Direct measurement and properties. Proc. Natl. Acad. Sci. USA 1971, 68, 1264-1268.

44. Kasuga, M.; Karlsson, F.A.; Kahn, C.R. Insulin stimulates the phosphorylation of the 95,000-Dalton subunit of its own receptor. Science 1982, 215, 185-187.

45. Roth, R.A.; Cassell, D.J. Insulin Receptor-Evidence that it is a protein kinase. Science 1983, 219, 299-301.

46. Ebina, Y.; Ellis, L.; Jarnagin, K.; Edery, M.; Graf, L.; Clauser, E.; Ou, J.h.; Masiarz, F.; Kan, Y.; Goldfine, I.; et al. The human insulin receptor cDNA: The structural basis for hormone-activated transmembrane signalling. Cell 1985, 40, 747-758.

47. Ullrich, A.; Bell, J.R.; Chen, E.Y.; Herrera, R.; Petruzzelli, L.M.; Dull, T.J.; Gray, A.; Coussens, L.; Liao, Y.C.; Tsubokawa, M.; et al. Human insulin receptor and its relationship to the tyrosine kinase family of oncogenes. Nature 1985, 313, 756-761.

48. Ullrich, A.; Gray, A.; Tam, A.W.; Yangfeng, T.; Tsubokawa, M.; Collins, C.; Henzel, W.; Lebon, T.; Kathuria, S.; Chen, E.; et al. Insulin-like growth factor-I receptor primary structure-Comparison with insulin-receptor suggests structural determinants that define functional specificity. EMBO J. 1986, 5, 2503-2512.

49. De Meyts, P.; Whittaker, J. Structural biology of insulin and IGF1 receptors: Implications for drug design. Nat. Rev. Drug. Discov. 2002, 1, 769-783. 
50. Adams, T.E.; Epa, V.C.; Garrett, T.P.J.; Ward, C.W. Structure and function of the type 1 insulin-like growth factor receptor. Cell. Mol. Life Sci. 2000, 57, 1050-1093.

51. Hubbard, R.D.; Wilsbacher, J.L. Advances towards the development of ATP-competitive small-molecule inhibitors of the insulin-like growth factor receptor (IGF-IR). ChemMedChem 2007, 2, 41-46.

52. Ward, C.W.; Lawrence, M.C. Ligand-induced activation of the insulin receptor: A multi-step process involving structural changes in both the ligand and the receptor. BioEssays 2009, 31, 422-434.

53. Humbel, R.E. Insulin-like growth factors I and II. Eur. J. Biochem. 1990, 190, 445-462.

54. Cohick, W.; Clemmons, D. The insulin-like growth factors. Annu. Rev. Physiol. 1993, $55,131-153$.

55. Khandwala, H.M.; McCutcheon, I.E.; Flyvbjerg, A.; Friend, K.E. The effects of insulin-like growth factors on tumorigenesis and neoplastic growth. Endocr. Rev. 2000, 21, 215-244.

56. Zhang, X.; Yee, D. Tyrosine kinase signalling in breast cancer insulin-like growth factors and their receptors in breast cancer. Breast Cancer Res. 2000, 2, 170-175.

57. Yu, H.; Rohan, T. Role of the insulin-like growth factor family in cancer development and progression. J. Natl. Cancer Inst. 2000, 92, 1472-1489.

58. Leroith, D.; Roberts, C.T., Jr. The insulin-like growth factor system and cancer. Cancer Lett. 2003, 195, 127-137.

59. Denley, A.; Wang, C.X.C.; McNeil, K.A.; Walenkamp, M.J.E.; Duyvenvoorde, H.V.; Wit, J.M.; Wallace, J.C.; Norton, R.S.; Karperien, M.; Forbes, B.E. Structural and functional characteristics of the $\mathrm{Val}(44) \mathrm{Met}$ insulin-like growth factor I missense mutation: Correlation with effects on growth and development. Mol. Endocrinol. 2005, 19, 711-721.

60. Belfiore, A. The role of insulin receptor isoforms and hybrid Insulin/IGF-I receptors in human cancer. Curr. Pharm. Des. 2007, 13, 671-686.

61. Gschwind, A.; Fischer, O.M.; Ullrich, A. The discovery of receptor tyrosine kinases: Targets for cancer therapy. Nat. Rev. Cancer 2004, 4, 361-370.

62. Deyev, I.E.; Sohet, F.; Vassilenko, K.P.; Serova, O.V.; Popova, N.V.; Zozulya, S.A.; Burova, E.B.; Houillier, P.; Rzhevsky, D.I.; Berchatova, A.A.; et al. Insulin receptor-related receptor as an extracellular alkali sensor. Cell Metab. 2011, 13, 679-689.

63. Bhattacharya, A. Protein structures: Structures of desire. Nature 2009, 459, 24-27.

64. Hubbard, S.R.; Wei, L.; Elis, L.; Hendrickson, W.A. Crystal structure of the tyrosine kinase domain of the human insulin receptor. Nature 1994, 372, 746-754.

65. Hubbard, S.R. Crystal structure of the activated insulin receptor tyrosine kinase in complex with peptide substrate and ATP analog. EMBO J. 1997, 16, 5572-5581.

66. Favelyukis, S.; Till, J.H.; Hubbard, S.R.; Miller, W.T. Structure and autoregulation of the insulin-like growth factor 1 receptor kinase. Nat. Struct. Mol. Biol. 2001, 8, 1058-1063.

67. Munshi, S.; Kornienko, M.; Hall, D.L.; Reid, J.C.; Waxman, L.; Stirdivant, S.M.; Darke, P.L.; Kuo, L.C. Crystal structure of the Apo, unactivated insulin-like growth factor-1 receptor kinase implication for inhibitor specificity. J. Biol. Chem. 2002, 277, 38797-38802. 
68. Garrett, T.P.J.; McKern, N.M.; Lou, M.Z.; Frenkel, M.J.; Bentley, J.D.; Lovrecz, G.; Elleman, T.C.; Cosgrove, L.J.; Ward, C.W. Crystal structure of the first three domains of the type-1 insulin-like growth factor receptor. Nature 1998, 394, 395-399.

69. Tulloch, P.; Lawrence, L.; McKern, N.; Robinson, C.; Bentley, J.; Cosgrove, L.; Ivancic, N.; Lovrecz, G.; Siddle, K.; Ward, C. Single-molecule imaging of human insulin receptor ectodomain and its Fab complexes. J. Struc. Biol. 1999, 125, 11-18.

70. Lou, M.; Garrett, T.; McKern, N.; Hoyne, P.; Epa, V.; Bentley, J.; Lovrecz, G.; Cosgrove, L.; Frenkel, M.; Ward, C. The first three domains of the insulin receptor differ structurally from the insulin-like growth factor 1 receptor in the regions governing ligand specificity. Proc. Natl. Acad. Sci. USA 2006, 103, 12429-12434.

71. McKern, N.; Lawrence, M.; Streltsov, V.; Lou, M.; Adams, T.; Lovrecz, G.; Elleman, T.; Richards, K.; Bentley, J.; Pilling, P.; et al. Structure of the insulin receptor ectodomain reveals a folded-over conformation. Nature 2006, 443, 218-221.

72. Smith, B.J.; Huang, K.; Kong, G.; Chan, S.J.; Nakagawa, S.; Menting, J.G.; Hu, S.Q.; Whittaker, J.; Steiner, D.F.; Katsoyannis, P.G.; et al. Structural resolution of a tandem hormone-binding element in the insulin receptor and its implications for design of peptide agonists. Proc. Natl. Acad. Sci. USA 2010, 107, 6771-6776.

73. Whitten, A.E.; Smith, B.J.; Menting, J.G.; Margetts, M.B.; McKern, N.M.; Lovrecz, G.O.; Adams, T.E.; Richards, K.; Bentley, J.D.; Trewhella, J.; et al. Solution structure of ectodomains of the insulin receptor family: The ectodomain of the Type 1 insulin-like growth factor receptor displays asymmetry of ligand binding accompanied by limited conformational change. J. Mol. Biol. 2009, 394, 878-892.

74. Luo, R.Z.T.; Beniac, D.R.; Fernandes, A.; Yip, C.C.; Ottensmeyer, F.P. Quaternary structure of the insulin-insulin receptor complex. Science 1999, 285, 1077-1080.

75. Ward, C.; Lawrence, M.; Streltsov, V.; Adams, T.; McKern, N. The insulin and EGF receptor structures: New insights into ligand-induced receptor activation. Trends Biochem. Sci. 2007, 32, 129-137.

76. Menting, J.G.; Whittaker, J.; Margetts, M.B.; Whittaker, L.J.; Kong, G.K.W.; Smith, B.J.; Watson, C.J.; Žáková, L.; Kletvíková, E.; Jiráček, J.; et al. How insulin engages its primary binding site on the insulin receptor. Nature 2013, 493, 241-245.

77. Menting, J.G.; Yang, Y.; Chan, S.J.; Phillips, N.B.; Smith, B.J.; Whittaker, J.; Wickramasinghe, N.P.; Whittaker, L.J.; Pandyarajan, V.; Wan, Z.L.; et al. Protective hinge in insulin opens to enable its receptor engagement. Proc. Natl. Acad. Sci. USA 2014, 111, E3395-E3404.

78. Li, Q.; Wong, Y.L.; Kang, C. Solution structure of the transmembrane domain of the insulin receptor in detergent micelles. Biochim. Biophys. Acta 2014, 1838, 1313-1321.

79. Ward, C.W.; Garrett, T.P. The relationship between the L1 and L2 domains of the insulin and epidermal growth factor receptors and leucine-rich repeat modules. BMC Bioinform. 2001, 2, 4.

80. Lawrence, M.; McKern, N.; Ward, C. Insulin receptor structure and its implications for the IGF-1 receptor. Curr. Opin. Struct. Biol. 2007, 17, 699-705. 
81. Ward, C.; Lawrence, M.; Streltsov, V.; Garrett, T.; McKern, N.; Lou, M.; Lovrecz, G.; Adams, T. Structural insights into ligand-induced activation of the insulin receptor. Acta Physiol. 2008, 192, 3-9.

82. Ward, C.; Lawrence, M. Similar but different: Ligand-induced activation of the insulin and epidermal growth factor receptor families. Curr. Opin. Struct. Biol. 2012, 22, 1-7.

83. Ward, C.W.; Menting, J.G.; Lawrence, M.C. The insulin receptor changes conformation in unforeseen ways on ligand binding: Sharpening the picture of insulin receptor activation. Bioessays 2013, 35, 945-954.

84. De Meyts, P. The structural basis of insulin and insulin-like growth factor-I receptor binding and negative co-operativity, and its relevance to mitogenic versus metabolic signalling. Diabetologia 1994, 37, S135-S148.

85. De Meyts, P. The insulin receptor: A prototype for dimeric, allosteric membrane receptors? Trends Biochem. Sci. 2008, 33, 376-384.

86. Jensen, M.; de Meyts, P. Molecular mechanisms of differential intracellular signaling from the insulin receptor. Vitam. Horm. 2009, 80, 51-75.

87. Hubbard, S.R.; Mohammadi, M.; Schlessinger, J. Autoregulatory mechanisms in protein-tyrosine kinases. J. Biol. Chem. 1998, 273, 11987-11990.

88. Hubbard, S.R.; Till, J.H. Protein tyrosine kinase structure and function. Annu. Rev. Biochem. 2000, 69, 373-398.

89. Hubbard, S.R. Juxtamembrane autoinhibition in receptor tyrosine kinases. Nat. Rev. Mol. Cell Biol. 2004, 5, 464-471.

90. Hubbard, S.R.; Miller, W.T. Receptor tyrosine kinases: Mechanisms of activation and signaling. Curr. Opin. Cell Biol. 2007, 19, 117-123.

91. Hubbard, S.R. Structural biology: Insulin meets its receptor. Nature 2013, 493, 171-172.

92. Kahn, C.R.; White, M. The insulin receptor and the molecular mechanism of insulin action. J. Clin. Invest. 1988, 82, 1151-1156.

93. Tavaré, J.M.; Siddle, K. Mutational analysis of insulin receptor function: Consensus and controversy. Biochim. Biophys. Acta 1993, 1178, 21-39.

94. White, M.F. The IRS-signalling system: A network of docking proteins that mediate insulin action. Mol. Cellul. Biochem. 1998, 182, 3-11.

95. Di Guglielmo, G.M.; Baass, P.C.; Authier, F.; Posner, B.I.; Bergeron, J.J. Insulin receptor internalization and signalling. Mol. Cellul. Biochem. 1998, 182, 59-63.

96. Marino-Buslje, C.; Martin-Martinez, M.; Mizuguchi, K.; Siddle, K.; Blundell, T. The insulin receptor: From protein sequence to structure. Biochem. Soc. Trans. 1999, 27, 715-726.

97. Kitamura, T.; Kahn, C.; Accili, D. Insulin receptor knockout mice. Annu. Rev. Physiol. 2003, 65, 313-332.

98. Ussar, S.; Vienberg, S.G.; Kahn, C.R. Receptor antibodies as novel therapeutics for diabetes. Sci. Transl. Med. 2011, 3, 113ps47.

99. Maruyama, I.N. Mechanisms of activation of receptor tyrosine kinases: Monomers or dimers. Cells 2014, 3, 304-330. 
100. Weiss, M.A. Proinsulin and the genetics of diabetes mellitus. J. Biol. Chem. 2009, 284, 19159-19163.

101. Kamrava, M.; Gius, D.; Casagrande, G.; Kohn, E. Will targeting insulin growth factor help us or hurt us?: An oncologist's perspective. Ageing Res. Rev. 2011, 10, 62-70.

102. Kaarsholm, N.C.; Ko, H.C.; Dunn, M.F. Comparison of solution structural flexibility and zinc binding domains for insulin, proinsulin, and miniproinsulin. Biochemistry 1989, 28, 4427-4435.

103. Roy, M.; Brader, M.L.; Lee, R.W.K.; Kaarsholm, N.C.; Hansen, J.F.; Dunn, M.F. Spectroscopic signatures of the $\mathrm{T}$ to $\mathrm{R}$ conformational transition in the insulin hexamer. J. Mol. Biol. 1989, 264, 19081-19085.

104. Berchtold, H.; Hilgenfeld, R. Binding of phenol to $\mathrm{R}_{6}$ insulin hexamers. Biopolymers 1999, $51,165-172$.

105. Sohma, Y.; Pentelute, B.L.; Whittaker, J.; Hua, Q.; Whittaker, L.J.; Weiss, M.A.; Kent, S.B.H. Comparative properties of insulin-like growth factor 1 (IGF-1) and [Gly7D-Ala]IGF-1 prepared by total chemical synthesis. Angew. Chem. Int. Ed. 2008, 47, 1102-1106.

106. Cosgrove, L.; Lovrecz, G.O.; Verkuylen, A.; Cavaleri, L.; Black, L.A.; Bentley, J.D.; Howlett, G.J.; Gray, P.P.; Ward, C.W.; McKern, N.M. Purification and properties of insulin receptor ectodomain from large-scale mammalian cell culture. Protein Expr. Purif. 1995, 6, 789-798.

107. Sparrow, L.G.; Gorman, J.J.; Strike, P.M.; Robinson, C.P.; McKern, N.M.; Epa, V.C.; Ward, C.W. The location and characterisation of the O-linked glycans of the human insulin receptor. Proteins 2007, 66, 261-265.

108. Sparrow, L.G.; Lawrence, M.C.; Gorman, J.J.; Strike, P.M.; Robinson, C.P.; McKern, N.M.; Ward, C.W. N-linked glycans of the human insulin receptor and their distribution over the crystal structure. Proteins 2008, 71, 426-439.

109. Massague, J.; Pilch, P.F.; Czech, M.P. Electrophoretic resolution of three major insulin receptor structures with unique subunit stoichiometries. Proc. Natl. Acad. Sci. USA 1980, 77, 7137-7141.

110. Sparrow, L.G.; McKern, N.M.; Gorman, J.J.; Strike, P.M.; Robinson, C.P.; Bentley, J.D.; Ward, C.W. The disulfide bonds in the C-terminal domains of the human insulin receptor ectodomain. J. Biol. Chem. 1997, 272, 29460-29467.

111. Vashisth, H.; Abrams, C. Docking of insulin to a structurally equilibrated insulin receptor ectodomain. Proteins 2010, 78, 1531-1543.

112. Vashisth, H.; Abrams, C. All-atom structural models for complexes of insulin-like growth factors IGF1 and IGF2 with their cognate receptor. J. Mol. Biol. 2010, 400, 645-658.

113. Pullen, R.; Lindsay, D.; Wood, S.; Tickle, I.; Blundell, T.; Wollmer, A.; Krail, G.; Brandenburg, D.; Zahn, H.; Gliemann, J.; Gammeltoft, S. Receptor-binding region of insulin. Nature 1976, 259, 369-373.

114. De Meyts, P.; Obberghen, E.; Roth, J.; Wollmer, A.; Brandenburg, D. Mapping of the residues responsible for the negative cooperativity of the receptor-binding region of insulin. Nature 1978, $273,504-509$. 
115. Kristensen, C.; Kjeldsen, T.; Wiberg, F.; Schäffer, L.; Hach, M.; Havelund, S.; Bass, J.; Steiner, D.; Andersen, A. Alanine scanning mutagenesis of insulin. J. Biol. Chem. 1997, 272, 12978-12983.

116. Chen, H.; Shi, M.; Guo, Z.; Tang, Y.; Qiao, Z.; Liang, Z.; Feng, Y. Four new monomeric insulins obtained by alanine scanning the dimer-forming surface of the insulin molecule. Protein Eng. 2000, 13, 779-782.

117. Nakamura, T.; Takahashi, H.; Takahashi, M.; Shimba, N.; Suzuki, E.I.; Shimada, I. Direct determination of the insulin-insulin receptor interface using transferred cross-saturation experiments. J. Med. Chem. 2010, 53, 1917-1922.

118. Williams, P.; Mynarcik, D.; Yu, G.; Whittaker, J. Mapping of an $\mathrm{NH}_{2}$-terminal ligand binding site of the insulin receptor by alanine scanning mutagenesis. J. Biol. Chem. 1995, 270, 3012-3016.

119. Whittaker, J.; Whittaker, L. Characterization of the functional insulin binding epitopes of the full-length insulin receptor. J. Biol. Chem. 2005, 280, 20932-20936.

120. Mynarcik, D.; Williams, P.; Schaffer, L.; Yu, G.; Whittaker, J. Analog binding properties of insulin receptor mutants. J. Biol. Chem. 1997, 272, 2077-2081.

121. Schaefer, E.; Siddle, K.; Ellis, L. Deletion analysis of the human insulin receptor ectodomain reveals independently folded soluble subdomains and insulin binding by a monomeric $\alpha$-subunit. J. Biol. Chem. 1990, 265, 13248-13253.

122. Kristensen, C.; Andersen, A.; Hach, M.; Wiberg, F.; Schäffer, L.; Kjeldsen, T. A single-chain insulin-like growth factor I/insulin hybrid binds with high affinity to the insulin receptor. Biochem. J. 1995, 305, 981-986.

123. Schlein, M.; Havelund, S.; Kristensen, C.; Dunn, M.; Kaarsholm, N. Ligand-induced conformational change in the minimized insulin receptor. J. Mol. Biol. 2000, 303, 161-169.

124. Brandt, J.; Andersen, A.; Kristensen, C. Dimeric fragment of the insulin receptor $\alpha$-subunit binds insulin with full holoreceptor affinity. J. Biol. Chem. 2001, 276, 12378-12384.

125. Surinya, K.; Molina, L.; Soos, M.; Brandt, J.; Kristensen, C.; Siddle, K. Role of insulin receptor dimerization domains in ligand binding, cooperativity, and modulation by anti-receptor antibodies. J. Biol. Chem. 2002, 277, 16718-16725.

126. Kristensen, C.; Andersen, A.; Østergaard, S.; Hansen, P.; Brandt, J. Functional reconstitution of insulin receptor binding site from non-binding receptor fragments. J. Biol. Chem. 2002, 277, 18340-18345.

127. Kurose, T.; Pashmforoush, M.; Yoshimasa, Y.; Carroll, R.; Schwartz, G.; Burke, G.; Katsoyannis, P.; Steiner, D. Cross-linking of a B25 Azidophenylalanine insulin derivative to the carboxyl-terminal regions of the $\alpha$-subunit of the insulin receptor. J. Biol. Chem. 1994, 269, 29190-29197.

128. Mynarcik, D.; Yu, G.; Whittaker, J. Alanine-scanning mutagenesis of a C-terminal ligand binding domain in the insulin receptor $\alpha$ subunit. J. Biol. Chem. 1996, 271, 2439-2442.

129. Kristensen, C.; Wiberg, F; Andersen, A. Specificity of insulin and insulin-like growth factor I receptors investigated using chimeric mini-receptors. J. Biol. Chem. 1999, 274, 37351-37356.

130. Molina, L.; Marino-Buslje, C.; Quinn, D.; Siddle, K. Structural domains of the insulin receptor and IGF receptor required for dimerization and ligand binding. FEBS Lett. 2000, 467, 226-230. 
131. Whittaker, L.; Hao, C.; Fu, W.; Whittaker, J. High-affinity insulin binding: Insulin interacts with two receptor ligand binding sites. Biochemistry 2008, 47, 12900-12909.

132. Zhang, B.; Roth, R. A region of the insulin receptor important for ligand binding (residues 450-601) is recognized by patients' autoimmune antibodies and inhibitory monoclonal antibodies. Proc. Natl. Acad. Sci. USA 1991, 88, 9858-9862.

133. Fabry, M.; Schaefer, E.; Ellis, L.; Kojro, E.; Fahrenholz, F.; Brandenburg, D. Detection of a new hormone contact site within the insulin receptor ectodomain by the use of a novel photoreactive insulin. J. Biol. Chem. 1992, 267, 8950-8956.

134. Schumacher, R.; Soos, M.; Schlessinger, J.; Brandenburg, D.; Siddle, K.; Ullrich, A. Signaling-competent receptor chimeras allow mapping of major insulin receptor binding domain determinants. J. Biol. Chem. 1993, 268, 1087-1094.

135. Hao, C.; Whittaker, L.; Whittaker, J. Characterization of a second ligand binding site of the insulin receptor. Biochem. Biophys. Res. Commun. 2006, 347, 334-339.

136. Benyoucef, S.; Surinya, K.; Hadaschik, D.; Siddle, K. Characterization of insulin/IGF hybrid receptors: Contributions of the insulin receptor L2 and Fn1 domains and the alternatively spliced exon 11 sequence to ligand binding and receptor activation. Biochem. J. 2007, 403, 603-613.

137. Renteria, M.; Gandhi, H.; Vinuesa, P.; Helmerhorst, E.; Mancera, R. A comparative structural bioinformatics analysis of the insulin receptor family ectodomain based on phylogenetic information. PLoS One 2008, 3, e3667.

138. Bayne, M.L.; Applebaum, J.; Chicchi, G.G.; Hayes, N.S.; Green, B.G.; Cascieri, M.A. Structural analogs of human insulin-like growth factor-I with reduced affinity for serum binding-proteins and the type-2 insulin-like growth-factor receptor. J. Biol. Chem. 1988, 263, 6233-6239.

139. Cascieri, M.A.; Chicchi, G.G.; Applebaum, J.; Hayes, N.S.; Green, B.G.; Bayne, M.L. Identification of the domains of IGF-I responsible for high-affinity binding to the type-1 and type-2 IGF receptors (IGF-R1, IGF-R2), insulin-receptor (IR) and binding-proteins (BP). FASEB J. 1988, 2, A1773.

140. Cascieri, M.A.; Chicchi, G.G.; Applebaum, J.; Green, B.G.; Hayes, N.S.; Bayne, M.L. Structural analogs of human insulin-like growth-factor (IGF)-I with altered affinity for type-2 IGF receptors. J. Biol. Chem. 1989, 264, 2199-2202.

141. Bayne, M.L.; Applebaum, J.; Chicchi, G.G.; Miller, R.E.; Cascieri, M.A. The roles of Tyrosine-24, Tyrosine-31, and Tyrosine-60 in the high-affinity binding of insulin-like growth factor-I to the type-I insulin-like growth-factor receptor. J. Biol. Chem. 1990, 265, 15648-15652.

142. Sakano, K.I.; Enjoh, T.; Numata, F.; Fujiwara, H.; Marumoto, Y.; Higashihashi, N.; Sato, Y.; Perdue, J.F.; Fujitayamaguchi, Y. The design, expression, and characterization of human insulin-like growth factor-II (IGF-II) mutants specific for either the IGF-II cation-independent Mannose 6-Phosphate receptor or IGF-1 receptor. J. Biol. Chem. 1991, 266, 20626-20635.

143. Roth, B.V.; Burgisser, D.M.; Luthi, C.; Humbel, R.E. Mutants of human insulin-like growth factor-II-Expression and characterization of analogs with a substitution of $\mathrm{Tyr}^{27}$ and/or a deletion of residues 62-67. Biochem. Biophys. Res. Commun. 1991, 181, 907-914. 
144. Burgisser, D.M.; Roth, B.V.; Giger, R.; Luthi, C.; Weigl, S.; Zarn, J.; Humbel, R.E. Mutants of human insulin-like growth factor-II with altered affinities for the type-1 and type-2 insulin-like growth-factor receptor. J. Biol. Chem. 1991, 266, 1029-1033.

145. King, R.; Wells, J.R.E.; Krieg, P.; Snoswell, M.; Brazier, J.; Bagley, C.J.; Wallace, J.C.; Ballard, F.J.; Ross, M.; Francis, G.L. Production and characterization of recombinant insulin-like growth-factor-I (IGF-I) and potent analogs of IGF-I, with Gly or Arg substituted for Glu3, following their expression in Escherichia-Coli as fusion proteins. J. Mol. Endocrinol. 1992, $8,29-41$.

146. Francis, G.L.; Ross, M.; Ballard, F.J.; Milner, S.J.; Senn, C.; McNeil, K.A.; Wallace, J.C.; King, R.; Wells, J.R.E. Novel recombinant fusion protein analogs of insulin-like growth-factor (IGF)-1 indicate the relative importance of IGF-binding protein and receptor-binding for enhanced biological potency. J. Mol. Endocrinol. 1992, 8, 213-223.

147. Luthi, C.; Roth, B.V.; Humbel, R.E. Mutants of human insulin-like growth factor-II (IGF-II)-Expression and characterization of truncated IGF-II and of 2 naturally-occurring variants. Eur. J. Biochem. 1992, 205, 483-490.

148. Zhang, W.G.; Gustafson, T.A.; Rutter, W.J.; Johnson, J.D. Positively charged side-chains in the insulin-like growth-factor-I C-regions and D-regions determine receptor-binding specificity. J. Biol. Chem. 1994, 269, 10609-10613.

149. Hodgson, D.R.; May, F.; Westley, B.R. Mutations at position-11 and position-60 of insulin-like growth factor-1 reveal differences between its interactions with the type-I insulin-like-growth-factor receptor and the insulin receptor. Eur. J. Biochem. 1995, 233, 299-309.

150. Shooter, G.K.; Magee, B.; Soos, M.A.; Francis, G.L.; Siddle, K.; Wallace, J.C. Insulin-like growth factor (IGF)-I A- and B-domain analogues with altered type 1 IGF and insulin receptor binding specificities. J. Mol. Endocrinol. 1996, 17, 237-246.

151. Hodgson, D.R.; May, F.; Westley, B.R. Involvement of phenylalanine 23 in the binding of IGF-1 to the insulin and type I IGF receptor. Regul. Peptides 1996, 66, 191-196.

152. Jansson, M.; Uhlen, M.; Nilsson, B. Structural changes in insulin-like growth factor (IGF) I mutant proteins affecting binding kinetic rates to IGF binding protein 1 and IGF-I receptor. Biochemistry 1997, 36, 4108-4117.

153. Jansson, M.; Andersson, G.; Uhlen, M.; Nilsson, B.; Kordel, J. The insulin-like growth factor (IGF)binding protein 1 binding epitope on IGF-I probed by heteronuclear NMR spectroscopy and mutational analysis. J. Biol. Chem. 1998, 273, 24701-24707.

154. Yandell, C.A.; Francis, G.L.; Wheldrake, J.F.; Upton, Z. Kangaroo IGF-II is structurally and functionally similar to the human [Ser(29)]-IGF-II variant. J. Endocrinol. 1999, 161, 445-453.

155. Magee, B.A.; Shooter, G.K.; Wallace, J.C.; Francis, G.L. Insulin-like growth factor I and its binding proteins: A study of the binding interface using B-domain analogues. Biochemistry 1999, 38, 15863-15870.

156. Dubaquie, Y.; Mortensen, D.L.; Intintoli, A.; Hogue, D.A.; Nakamura, G.; Rancatore, P.; Lester, P.; Sadick, M.D.; Filvaroff, E.; Fielder, P.J.; et al. Binding protein-3-selective insulin-like growth factor I variants: Engineering, biodistributions, and clearance. Endocrinology 2001, 142, 165-173. 
157. Forbes, B.E.; McNeil, K.A.; Scott, C.D.; Surinya, K.H.; Cosgrove, L.J.; Wallace, J.C. Contribution of residues A54 and L55 of the human insulin-like growth factor-II (IGF-II) A domain to type 2 IGF receptor binding specificity. Growth Factors 2001, 19, 163-173.

158. Sørensen, H.; Whittaker, L.; Hinrichsen, J.; Groth, A.; Whittaker, J. Mapping of the insulin-like growth factor II binding site of the type I insulin-like growth factor receptor by alanine scanning mutagenesis. FEBS Lett. 2004, 565, 19-22.

159. Gauguin, L.; Delaine, C.; Alvino, C.L.; McNeil, K.A.; Wallace, J.C.; Forbes, B.E.; de Meyts, P. Alanine scanning of a putative receptor binding surface of insulin-like growth factor-I. J. Biol. Chem. 2008, 283, 20821-20829.

160. Alvino, C.L.; McNeil, K.A.; Ong, S.C.; Delaine, C.; Booker, G.W.; Wallace, J.C.; Whittaker, J.; Forbes, B.E. A novel approach to identify two distinct receptor binding surfaces of insulin-like growth factor II. J. Biol. Chem. 2009, 284, 7656-7664.

161. Gauguin, L.; Klaproth, B.; Sajid, W.; Andersen, A.S.; McNeil, K.A.; Forbes, B.E.; de Meyts, P. Structural basis for the lower affinity of the insulin-like growth factors for the insulin receptor. J. Biol. Chem. 2008, 282, 2604-2613.

162. Andersen, A.S.; Kjeldsen, T.; Wiberg, F.C.; Christensen, P.M.; Ramussen, J.S.; Norris, K.; Møller, K.B.; Møller, N.P.H. Changing the insulin-receptor to possess insulin-like growth factor-I ligand specificity. Biochemistry 1990, 29, 7363-7366.

163. Kjeldsen, T.; Andersen, A.S.; Wiberg, F.C.; Ramussen, J.S.; Schaffer, L.; Balschmidt, P.; Møller, K.B.; Møller, N.P.H. The ligand specificities of the insulin-receptor and the insulin-like growth factor-I receptor reside in different regions of a common binding-site. Proc. Natl. Acad. Sci. USA 1991, 88, 4404-4408.

164. Schumacher, R.; Mosthaf, L.; Schlessinger, J.; Brandenburg, D.; Ullrich, A. Insulin and insulin-like growth factor-I binding-specificity is determined by distinct regions of their cognate receptors. J. Biol. Chem. 1991, 266, 19288-19295.

165. Zhang, B.; Roth, R.A. Binding-properties of chimeric insulin-receptors containing the cysteine-rich domain of either the insulin-like growth factor-I receptor or the insulin-receptor related receptor. Biochemistry 1991, 30, 5113-5117.

166. Hoyne, P.A.; Cosgrove, L.J.; Mckern, N.M.; Bentley, J.D.; Ivancic, N.; Elleman, T.C.; Ward, C.W. High affinity insulin binding by soluble insulin receptor extracellular domain fused to a leucine zipper. FEBS Lett. 2000, 479, 15-18.

167. Gill, R.; Wallach, B.; Verma, C.; Urso, B.; de Wolf, E.; Grotzinger, J.; Murray-Rust, J.; Pitts, J.; Wollmer, A.; de Meyts, P.; et al. Engineering the C-region of human insulin-like growth factor-1: Implications for receptor binding. Prot. Eng. 1996, 9, 1011-1019.

168. Keyhanfar, M.; Booker, G.W.; Whittaker, J.; Wallace, J.C.; Forbes, B.E. Precise mapping of an IGF-I-binding site on the IGF-1R. Biochem. J. 2007, 401, 269-277.

169. Kiselyov, V.; Versteyhe, S.; Gauguin, L.; de Meyts, P. Harmonic oscillator model of the insulin and IGF1 receptors' allosteric binding and activation. Mol. Syst. Biol. 2009, 5, 1-12.

170. De Meyts, P. Insulin interactions with its receptors: Experimental evidence for negative coooperativity. Biochem. Biophys. Res. Comm. 1973, 55, 154-161. 
171. De Meyts, P.; Bianco, A.R.; Roth, J. Site-site interactions among insulin receptors: Characterization of the negative cooperativity. J. Biol. Chem. 1976, 251, 1877-1888.

172. Frenkel, D.; Smit, B. Understanding Molecular Simulations: From Algorithms to Applications, 2nd ed.; Academic Press: San Diego, CA, USA, 2002.

173. Leach, A.R. Molecular Modelling: Principles and Applications, 2nd ed.; Pearson Education Limited: Harlow, UK, 2001.

174. Schlick, T. Molecular Modeling and Simulation: An Interdisciplinary Guide, 1st ed.; Springer: New York, NY, USA, 2002.

175. Rapaport, D.C. The Art of Molecular Dynamics Simulation, 2nd ed.; Cambridge University Press: Cambridge, UK, 2004.

176. Karplus, M.; Petsko, G.A. Molecular dynamics simulations in biology. Nature 1990, 347, 631-639.

177. Karplus, M.; McCammon, J.A. Molecular dynamics simulations of biomolecules. Nat. Struct. Biol. 2002, 9, 646-652.

178. Karplus, M.; Kuriyan, J. Molecular dynamics and protein function. Proc. Natl. Acad. Sci. USA 2005, 102, 6679-6685.

179. MacKerell, A.D., Jr.; Bashford, D.; Bellott, M.; Dunbrack, R.L., Jr.; Evanseck, J.D.; Field, M.J.; Fischer, S.; Gao, J.; Guo, H.; Ha, S.; et al. All-atom empirical potential for molecular modeling and dynamics studies of proteins. J. Phys. Chem. B 1998, 102, 3586-3616.

180. MacKerell, A., Jr.; Feig, M.; Brooks, C, III. Extending the treatment of backbone energetics in protein force fields: Limitations of gas-phase quantum mechanics in reproducing protein conformational distributions in molecular dynamics simulations. J. Comput. Chem. 2004, $25,1400-1415$.

181. Andersen, H.C. Molecular dynamics simulations at constant pressure and/or temperature. J. Chem. Phys. 1980, 72, 2384-2393.

182. Berendsen, H.J.C.; Postma, J.P.M.; Gunsteren, W.F.V.; Dinola, A.; Haa, J.R. Molecular dynamics with coupling to an external bath. J. Chem. Phys. 1984, 81, 3684-3690.

183. Hoover, W.G.; Ladd, A.J.C.; Moran, C. High-strain-rate plastic-flow studied via non-equilibrium molecular dynamics. Phys. Rev. Lett. 1982, 48, 1818-1820.

184. Nosé, S. A molecular dynamics method for simulations in the canonical ensemble. Mol. Phys. 1984, 52, 255-268.

185. Hoover, W.G. Canonical dynamics-Equilibrium phase-space distributions. Phys. Rev. A 1985, 31, 1695-1697.

186. Kalé, L.; Skeel, R.; Bhandarkar, M.; Brunner, R.; Gursoy, A.; Krawetz, N.; Phillips, J.; Shinozaki, A.; Varadarajan, K.; Schulten, K. NAMD2: Greater scalability for parallel molecular dynamics. J. Comput. Phys. 1999, 151, 283-312.

187. Phillips, J.; Braun, R.; Wang, W.; Gumbart, J.; Tajkhorshid, E.; Villa, E.; Chipot, C.; Skeel, R.; Kalé, L.; Schulten, K. Scalable molecular dynamics with NAMD. J. Comput. Chem. 2005, $26,1781-1802$.

188. Humphrey, W.; Dalke, A.; Schulten, K. VMD-Visual Molecular Dynamics. J. Mol. Graph. 1996, $14,33-38$. 
189. Van Gunsteren, W.F.; Mark, A.E. Validation of molecular dynamics simulation. J. Chem. Phys. 1998, 108, 6109-6116.

190. Metropolis, N.; Rosenbluth, A.W.; Rosenbluth, M.N.; Teller, A.N.; Teller, E. Equation of state calculations by fast computing machines. J. Chem. Phys. 1953, 21, 1087-1092.

191. Vashisth, H.; Abrams, C.F. All-atom structural models of insulin binding to the insulin receptor in the presence of a tandem hormone-binding element . Proteins 2013, 81, 1017-1030.

192. Vashisth, H.; Maragliano, L.; Abrams, C.F. "DFG-flip" in the insulin receptor kinase is facilitated by a helical intermediate state of the activation loop . Biophys. J. 2012, 102, 1979-1987.

193. Vashisth, H.; Skiniotis, G.; Brooks III, C.L. Collective variable approaches for single molecule flexible fitting and enhanced sampling. Chem. Rev. 2014, 114, 3353-3365.

194. Abrams, C.; Bussi, G. Enhanced sampling in molecular dynamics using metadynamics, replica-exchange, and temperature-acceleration. Entropy 2013, 16, 163-199.

195. Maragliano, L.; Vanden-Eijnden, E. A temperature accelerated method for sampling free energy and determining reaction pathways in rare events simulations. Chem. Phys. Lett. 2006, 426, 168-175.

196. Maragliano, L.; Vanden-Eijnden, E. Single-sweep methods for free energy calculations. J. Chem. Phys. 2008, 128, 184110.

197. Abrams, C.F.; Vanden-Eijnden, E. Large-scale conformational sampling of proteins using temperature-accelerated molecular dynamics. Proc. Natl. Acad. Sci. USA 2010, 107, 4961-4966.

198. Vashisth, H.; Skiniotis, G.; Brooks, C.L, III. Using enhanced sampling and structural restraints to refine atomic structures into low-resolution electron microscopy maps. Structure 2012, 20, 1453-1462.

199. Vashisth, H.; Brooks, C. L., III. Conformational sampling of maltose-transporter components in Cartesian collective variables is governed by the low-frequency normal modes. $J$. Phys. Chem. Lett. 2012, 3, 3379-3384.

200. Vashisth, H.; Storaska, A.J.; Neubig, R.R.; Brooks, C. L., III. Conformational dynamics of a regulator of G-protein signaling protein reveals a mechanism of allosteric inhibition by a small molecule . ACS Chem. Biol. 2013, 8, 2778-2784.

201. Selwa, E.; Huynh, T.; Ciccotti, G.; Maragliano, L.; Malliavin, T.E. Temperature-accelerated molecular dynamics gives insights into globular conformations sampled in the free state of the AC catalytic domain. Proteins 2014, 82, 2483-2496.

202. Naveh, Z.M.H.; Malliavin, T.E.; Maragliano, L.; Cottone, G.; Ciccotti, G. Conformational changes in acetylcholine binding protein investigated by temperature accelerated molecular dynamics. PLoS One 2014, 9, e88555.

203. Maragliano, L.; Fischer, A.; Vanden-Eijnden, E.; Ciccotti, G. String method in collective variables: Minimum free energy paths and isocommittor surfaces. J. Chem. Phys. 2006, 125, 024106.

204. McCammon, J.A.; Gelin, B.R.; Karplus, M. Dynamics of folded proteins. Nature 1977, 267, 585-590.

205. Wodak, S.J.; Alard, P.; Delhaise, P.; Renneboogsquilbin, C. Simulation of conformational changes in $2 \mathrm{ZN}$ insulin. J. Mol. Biol. 1985, 181, 317-322. 
206. Krüger, P.; Strassburger, W.; Wollmer, A.; Gunsteren, W.F.V.; Dodson, G.G. The simulated dynamics of the insulin monomer and their relationship to the molecules structure. E. Biophys. J. 1987, 14, 449-459.

207. Mark, A.E.; Berendsen, H.J.C.; Gunsteren, W.F.V. Conformational flexibility of aqueous monomeric and dimeric insulin: A molecular dynamics study. Biochemistry 1991, 30, 10866-10872.

208. Krüger, P.; Hahnen, J.; Wollmer, A. Comparative studies on the dynamics of cross-linked insulin. Euro. Biophys. J. 1994, 23, 177-187.

209. Tidor, B.; Karplus, M. The contribution of vibrational entropy to molecular association: The dimerization of insulin. J. Mol. Biol. 1994, 238, 405-414.

210. Falconi, M.; Cambria, M.T.; Cambria, A.; Desideri, A. Structure and stability of the insulin dimer investigated by molecular dynamics simulation. J. Bimol. Struc. Dynamics 2001, 18, 761-772.

211. Budi, A.; Legge, S.; Treutlein, H.; I. Yarovsky, I. Effect of external stresses on protein conformation: A computer modelling study. Euro. Biophys. J. 2004, 33, 121-129.

212. Zoete, V.; Meuwly, M.; Karplus, M. A comparison of the dynamic behavior of monomeric and dimeric insulin shows structural rearrangements in the active monomer. J. Mol. Biol. 2004, 342, 913-929.

213. Isralewitz, B.; Gao, M.; Schulten, K. Steered molecular dynamics and mechanical functions of proteins. Curr. Op. Struct. Biol. 2001, 11, 224-230.

214. Kim, T.; Rhee, A.; Yip, C.M. Force-induced insulin dimer dissociation: A molecular dynamics study. J. Am. Chem. Soc. 2006, 128, 5330-5331.

215. Zoete, V.; Meuwly, M. Importance of individual side chains for the stability of a protein fold: Computational alanine scanning of the insulin monomer. J. Comp. Chem. 2006, 27, 1843-1857.

216. Legge, F.S.; Budi, A.; Treutlein, H.; Yarovsky, I. Protein flexibility: Multiple molecular dynamics simulations of insulin chain B. Biophys. Chem. 2006, 119, 146-157.

217. Todorova, N.; Marinelli, F.; Piana, S.; Yarovsky, I. Exploring the folding free energy landscape of insulin using bias exchange metadynamics. J. Phys. Chem. B 2009, 113, 3556-3564.

218. Schlitter, J.; Engels, M.; Krüger, P.; Jacoby, E.; Wollmer, A. Targeted molecular dynamics simulation of conformational change - application to the $\mathrm{T} \rightarrow \mathrm{R}$ transition in insulin. Mol. Simul. 1993, 10, 291-308.

219. Jacoby, E.; Krüger, P.; Schlitter, J.; Roper, D.; Wollmer, A. Simulation of a complex protein structural change: The $\mathrm{T} \Longleftrightarrow \mathrm{R}$ transition in the insulin hexamer. Prot. Eng. 1996, 9, 113-125.

220. Badger, J.; Caspar, D. Water structure in cubic insulin crystals. Proc. Natl. Acad. Sci. USA 1991, $88,622-626$.

221. Chai, C.C.; Jhon, M.S. Molecular Dynamics Study on Protein and it's Water Structure at High Pressure. Mol. Sim. 2000, 23, 257-274.

222. Bagchi, K.; Roy, S. Sensitivity of water dynamics to biologically significant surfaces of monomeric insulin: Role of topology and electrostatic interactions. J. Phys. Chem. B 2014, 118, 3805-3813.

223. Vashisth, H.; Abrams, C.F. Ligand escape pathways and (Un)binding free energy calculations for the hexameric insulin-phenol complex. Biophys. J. 2008, 95, 4193-4204. 
224. Swegat, W.; Schlitter, J.; Krüger, P.; Wollmer, A. MD simulation of protein-ligand interaction: Formation and dissociation of an insulin-phenol complex. Biophys. J. 2003, 84, 1493-1506.

225. Vashisth, H. Flexibility in the insulin receptor ectodomain enables docking of insulin in crystallographic conformation observed in hormone-bound microreceptor. Membranes 2014, 4, 730-746.

226. Schäffer, L. A model for insulin binding to the insulin receptor. Eur. J. Biochem. 1994, 221, 1127-1132.

227. Soos, M.; Field, C.; Lammers, R.; Ullrich, A.; Zhang, B.; Roth, R.; Andersen, A.; Kjeldsen, T.; Siddle, K. A panel of monoclonal antibodies for the type I insulin-like growth factor receptor. Epitope mapping, effects on ligand binding, and biological activity. J. Biol. Chem. 1992, 267, 12955-12963.

228. Kadowaki, H.; Kadowaki, T.; Cama, A.; Marcus-Samuels, B.; Rovira, A.; Bevins, C.; Taylor, S. Mutagenesis of lysine 460 in the human insulin receptor. Effects upon receptor recycling and cooperative interactions among binding sites. J. Biol. Chem. 1990, 265, 21285-21296.

229. Christoffersen, C.T.; Bornfeldt, K.E.; Rotella, C.M.; Gonzales, N.; Vissing, H.; Shymko, R.M.; Tenhoeve, J.; Groffen, J.; Heisterkamp, N.; de Meyts, P. Negative cooperativity in the insulin-like growth-factor-I receptor and a chimeric IGF/Insulin receptor. Endocrinology 1994, 135, 472-475.

230. Chan, S.J.; Nakagawa, S.; Steiner, D.F. Complementation analysis demonstrates that insulin cross-links both $\alpha$-subunits in a truncated insulin receptor dimer. J. Biol. Chem. 2007, 282, 13754-13758.

231. Whittaker, J.; Garcia, P.; Yu, G.; Mynarcik, D. Transmembrane domain interactions are necessary for negative cooperativity of the insulin-receptor. Mol. Endocrinol. 1994, 8, 1521-1526.

232. Bass, J.; Kurose, T.; Pashmforoush, M.; Steiner, D.F. Fusion of insulin receptor ectodomains to immunoglobulin constant domains reproduces high-affinity insulin binding in vitro. J. Biol. Chem. 1996, 271, 19367-19375.

233. Surinya, K.H.; Forbes, B.E.; Occhiodoro, F.; Booker, G.W.; Francis, G.L.; Siddle, K.; Wallace, J.C.; Cosgrove, L.J. An investigation of the ligand binding properties and negative cooperativity of soluble insulin-like growth factor receptors. J. Biol. Chem. 2008, 283, 5355-5363.

234. Slaaby, R.; Schaffer, L.; Lautrup-Larsen, I.; Andersen, A.S.; Shaw, A.C.; Mathiasen, I.S.; Brandt, J. Hybrid receptors formed by insulin receptor (IR) and insulin-like growth factor I receptor (IGF-IR) have low insulin and high IGF-1 affinity irrespective of the IR splice variant. J. Biol. Chem. 2006, 281, 25869-25874.

235. Cara, J.F.; Mirmira, R.G.; Nakagawa, S.H.; Tager, H.S. An insulin-like growth factor-I insulin hybrid exhibiting high potency for interaction with the type-I insulin-like growth-factor and insulin-receptors of placental plasma-membranes. J. Biol. Chem. 1990, 265, 17820-17825.

236. DeWolf, E.; Gill, R.; Geddes, S.; Pitts, J.; Wollmer, A.; Grotzinger, J. Solution structure of a mini IGF-1. Prot. Sci. 1996, 5, 2193-2202.

237. Denley, A.; Bonython, E.R.; Booker, G.W.; Cosgrove, L.J.; Forbes, B.E.; Ward, C.W.; Wallace, J.C. Structural determinants for high-affinity binding of insulin-like growth factor 
II to insulin receptor (IR)-A, the exon 11 minus isoform of the IR. Mol. Endocrinol. 2004, $18,2502-2512$.

238. Bayne, M.L.; Applebaum, J.; Underwood, D.; Chicchi, G.G.; Green, B.G.; Hayes, N.S.; Cascieri, M.A. The C-region of human insulin-like growth factor (IGF) I is required for high-affinity binding to the type-1 IGF receptor. J. Biol. Chem. 1988, 264, 11004-11008.

239. Epa, V.C.; Ward, C.W. Model for the complex between the insulin-like growth factor I and its receptor: Towards designing antagonists for the IGF-I receptor. Protein Eng. Des. Sel. 2006, 19, 377-384.

240. Xu, B.; Huang, K.; Chu, Y.C.; Hu, S.Q.; Nakagawa, S.; Wang, S.; Wang, R.Y.; Whittaker, J.; Katsoyannis, P.G.; Weiss, M. Decoding the cryptic active conformation of a protein by synthetic photoscanning: Insulin inserts a detachable arm between receptor domains. J. Biol. Chem. 2009, 284, 14597-14608.

241. Whittaker, J.; Whittaker, L.; Roberts, C., Jr.; Phillips, N.; Ismail-Beigi, F.; Lawrence, M.; Weiss, M. $\alpha$-Helical element at the hormone-binding surface of the insulin receptor functions as a signaling element to activate its tyrosine kinase. Proc. Natl. Acad. Sci. USA 2012, $109,11166-71$.

242. Huang, K.; Chan, S.; Hua, Q.; Chu, Y.; Wang, R.; Klaproth, B.; Jia, W.; Whittaker, J.; de Meyts, P.; Nakagawa, S.; et al. The A-chain of insulin contacts the insert domain of the insulin receptor. J. Biol. Chem. 2007, 282, 35337-35349.

243. Menting, J.; Ward, C.; Margetts, M.; Lawrence, M. A thermodynamic study of ligand binding to the first three domains of the human insulin receptor: Relationship between the receptor alpha-chain C-terminal peptide and the site-1 insulin mimetic peptides. Biochemistry 2009, 48, 5492-5500.

244. Pillutla, R.C.; Hsiao, K.C.; Beasley, J.R.; Brandt, J.; Ostergaard, S.; Hansen, P.H.; Spetzler, J.C.; Danielsen, G.M.; Andersen, A.S.; Brissette, R.E.; et al. Peptides identify the critical hotspots involved in the biological activation of the insulin receptor. J. Biol. Chem. 2002, 277, 22590-22594.

245. Schaffer, L.; Brissette, R.E.; Spetzler, J.C.; Pillutla, R.C.; Ostergaard, S.; Lennick, M.; Brandt, J.; Fletcher, P.W.; Danielsen, G.M.; Hsiao, K.C.; et al. Assembly of high-affinity insulin receptor agonists and antagonists from peptide building blocks. Proc. Natl. Acad. Sci. USA 2003, $100,4435-4439$.

246. Derewenda, U.; Derewenda, Z.; Dodson, E.J.; Dodson, G.G.; Bing, X.; Markussen, J. X-ray analysis of the single chain B29-A1 peptide-linked insulin molecule. A completely inactive analogue. J. Mol. Biol. 1991, 220, 425-433.

247. Mirmira, R.; Nakagawa, S.; Tager, H. Importance of the character and configuration of residues B24, B25, and B26 in insulin-receptor interactions. J. Biol. Chem. 1991, 266, 1428-1436.

248. Hua, Q.X.; Shoelson, S.E.; Kochoyan, M.; Weiss, M. Receptor-binding redefined by a structural switch in a mutant human insulin. Nature 1991, 354, 238-241.

249. Hua, Q.X.; Xu, B.; Huang, K.; Hu, S.Q.; Nakagawa, S.; Jia, W.; Wang, S.; Whittaker, J.; Katsoyannis, P.G.; Weiss, M. Enhancing the activity of a protein by stereospecific unfolding: 
Conformational life cycle of insulin and its evolutionary origins. J. Biol. Chem. 2009, 284, 14586-14596.

250. Ellis, L.; Clauser, E.; Morgan, D.O.; Edery, M.; Roth, R.A.; Rutter, W.J. Replacement of insulin-receptor tyrosine residues 1162 and 1163 compromises insulin-stimulated kinase-activity and uptake of 2-deoxyglucose. Cell 1986, 45, 721-732.

251. Wilden, P.A.; Kahn, C.R.; Siddle, K.; White, M.F. Insulin-receptor kinase domain autophosphorylation regulates receptor enzymatic function. J. Biol. Chem. 1992, 267, 16660-16668.

252. Kornev, A.P.; Haste, N.M.; Taylor, S.S.; Ten Eyck, L.F. Surface comparison of active and inactive protein kinases identifies a conserved activation mechanism. Proc. Natl. Acad. Sci. USA 2006, 103, 17783-17788.

253. Kornev, A.P.; Taylor, S.S.; Ten Eyck, L.F. A helix scaffold for the assembly of active protein kinases. Proc. Natl. Acad. Sci. USA 2008, 105, 14377-14382.

254. Taylor, S.S.; Kornev, A.P. Protein kinases: Evolution of dynamic regulatory proteins. Trends Biochem. Sci. 2011, 36, 65-77.

255. Banavali, N.K.; Roux, B. Anatomy of a structural pathway for activation of the catalytic domain of Src kinase Hck. Proteins 2007, 67, 1096-1112.

256. Gan, W.; Yang, S.; Roux, B. Atomistic view of the conformational activation of Src kinase using the string method with swarms-of-trajectories. Biophys. J. 2009, 97, L8-L10.

257. Berteotti, A.; Cavalli, A.; Branduardi, D.; Gervasio, F.L.; Recanatini, M.; Parrinello, M. Protein conformational transitions: The closure mechanism of a kinase explored by atomistic simulations. J.Am. Chem. Soc. 2009, 131, 244-250.

258. Yang, S.; Banavali, N.K.; Roux, B. Mapping the conformational transition in Src activation by cumulating the information from multiple molecular dynamics trajectories. Proc. Natl. Acad. Sci. USA 2009, 106, 3776-3781.

259. Shan, Y.B.; Seeliger, M.A.; Eastwood, M.P.; Frank, F.; Xu, H.F.; Jensen, M.Ø.; Dror, R.O.; Kuriyan, J.; Shaw, D.E. A conserved protonation-dependent switch controls drug binding in the Abl kinase. Proc. Natl. Acad. Sci. USA 2009, 106, 139-144.

260. Flörke, R.; Schnaith, K.; Passlack, W.; Wichert, M.; Kuehn, L.; Fabry, M.; Federwisch, M.; Reinauer, H. Hormone-triggered conformational changes within the insulin-receptor ectodomain: Requirement for transmembrane anchors. Biochem. J. 2001, 360, 189-198.

261. Kavran, J.M.; McCabe, J.M.; Byrne, P.O.; Connacher, M.K.; Wang, Z.; Ramek, A.; Sarabipour, S.; Shan, Y.; Shaw, D.E.; Hristova, K.; et al. How IGF-1 activates its receptor. eLife 2014, 3, e03772.

262. Lee, J.; Miyazaki, M.; Romeo, G.R.; Shoelson, S.E. Insulin receptor activation with transmembrane domain ligands. J. Biol. Chem. 2014, 289, 19769-19777.

263. Hubbard, S.R.; Miller, W.T. Closing in on a mechanism for activation. eLife 2014, 3, e04909.

(c) 2015 by the author; licensee MDPI, Basel, Switzerland. This article is an open access article distributed under the terms and conditions of the Creative Commons Attribution license (http://creativecommons.org/licenses/by/4.0/). 